\title{
Issues in Development
}

\section{Commentary \\ The Role of Cell Migration in the Ontogeny of the \\ Lymphoid System}

\author{
MALCOLM A.S. MOORE
}

\begin{abstract}
The foundations of experimental hematology were laid by histologists, and while their contributions were enormous, they were limited in their interpretation of very dynamic processes by the static nature of the methodology. The middle of the twentieth century saw the introduction of techniques for hematopoietic cell marking and development of in vitro and in vivo assays for primitive hematopoietic cells, allowing dynamic studies of hematopoiesis. Paralleling this was an understanding of cellular immunology with the discovery of the role of the thymus and the identification of $T$ and $B$ lymphocyte lineages. In the 1960s a series of ontogenetic studies in birds and subsequently in mice revealed that hematopoietic and lymphoid development involved migration streams of primitive cells that colonized developing primary lymphoid organs as well as spleen, marrow, and liver. The yolk sac was proposed as the ultimate origin of these lympho-hematopoietic precursors. Subsequent studies identified a region associated with the dorsal aorta as the primary site of "definitive" stem cells. These opposing views are currently achieving a compromise that recognizes that both sites contribute stem cells involved in seeding the developing tissues. The clear distinction between the local origin of the inducing microenvironment provided by the endoderm or by stroma derived from mesenchymal stem cells of mesodermal origin, and the immigrant origin of the hematopoietic stem cells and progenitors, raises intriguing questions in the current climate of stem cell plasticity, cell fusion, and discovery of stem cells in adult marrow with the capacity to generate hematopoiesis as well as other mesodermal, ectodermal, and endodermal lineages.
\end{abstract}

\section{INTRODUCTION}

$\mathbf{T}$ His COMmentary is in part a personal historical perspective combined with a current review of the field, and in part a rebuttal to a commentary by Dr. Anastassova-Kristeva that appeared in this Journal (1) in which it was proposed that the currently accepted dogma of a common "lymphohematopoietic" stem cell origin of the lymphoid and hematopoietic system was in error. That commentary cited a publication of mine as supporting this position, to quote: "Moore and Owen (2) found that the thymocytes are produced from stem cells intrinsic to the thymic anlage by direct transformation of endodermal epithelial cells." This was a misquotation that completely reversed my conclusions. I was particularly pleased with this paper that was published in 1967 be- 
cause it was the culmination of my thesis work and basically challenged the then current dogma that thymic lymphoid cells arose by direct transformation of epithelium $(3,4)$. What I believe we clearly showed in that paper was that thymocytes are produced from stem/progenitor cells extrinsic to the thymic anlage that had exited from the circulation and invaded the thymic epithelial anlage. The epithelium did not form lymphocytes but provided the stromal environment supportive of thymic lymphopoisis. We also showed in the avian bursa of Fabricius, where B lymphocytes first develop, that the process also involved colonization of the epithelial buds by blood-borne stem/progenitor populations (5), rather than by intrinsic epithelial transformation as proposed by then current dogma (6). A later study of thymic development in Xenopus was initially interpreted as supporting the intrinsic epithelial origin of thymocytes $(7,8)$; however, subsequent studies by members of this group clearly showed an immigrant origin for thymic lymphoid precursors $(9,10)$. Other protagonists of the epithelial transformation theory also reversed their position in favor of an immigrant stem cell (11-13). The nature and origin of the cells that colonized the primary lymphoid organs has been a subject of debate and intense investigation over the last forty years, but there has been no serious challenge to the concept of circulating stem/progenitor cell populations migrating into organ anlages and initiating hematopoiesis in fetal liver and bone marrow and lymphopoiesis in thymus, bursa of Fabricius, and spleen $(2,5,14-17)$.

A simple question still remains unanswered: namely, why do stem and progenitor cells migrate through the circulation, and why are all lymphohematopoietic tissues dependent upon such extrinsic cells? A similar question can be posed in the case of primordial germ cells that also migrate through the embryo to the developing gonads. The concept of specific developmental niches or microenvironments can be evoked. These provide extrinsic signals that determine pluripotential stem cell fate. The yolk sac blood islands, generating both primitive and definitive generation stem and progenitor cells but supporting only primitive erythropoiesis, is one niche. The floor of the aorta is another niche where adult-type stem cells arise as well as definitive lymphoid and myeloid progenitors. The fetal liver provides the environment for extensive hematopoietic and B cells differentiation as well as stem cell amplification, while the epithelial niche of the thymus supports $\mathrm{T}$ lymphoid expansion and specialization but not stem cell survival. In this concept the lymphomyeloid stem cell is a tabula rasa whose differentiation fate is determined by the environment into which it has migrated. It is likely that this is not valid for the cells colonizing primary lymphoid organs since there is growing evidence for some degree of lymphoid commitment occurring prior to colonization, and consequently some degree of selection of colonizing cell types (e.g., by selective chemoattraction). An extraordinary array of extrinsic signals are provided by these microenvironments including members of the Wnt and hedgehog family, Notch ligands and a spectrum of hematopoietic growth factors, cytokines and chemokines, cytoadhesion molecules, and extracellular membrane components. A combination of functional and genomic analysis is beginning to unravel the nature of specific microenvironments and explain their ability to orchestrate the complex patterns of proliferation, self-renewal, and multi-lineage specification that characterize lymphohematopoiesis.

\section{HISTORICAL PERSPECTIVE}

Early attempts to understand the complexity of hematopoietic and lymphoid differentiation were limited by the available tools - the microscope and the stained slides revealed the static morphology of the tissues. Unfortunately this did not prevent the early observers from making dynamic interpretations of cell lineages and origin. In general they proved reasonably accurate when dealing with the later stages of hematopoietic differentiation. Problems arose when morphologically undifferentiated blast cells or mononuclear cells were endowed with various potentialities. There was also a great deal of controversy concerning "transitional" stages between, e.g., mesenchyme and endothelium and hematopoietic lineage, and between epithelium and lymphocyte. This was followed by dynamic studies that permitted analysis of cell fate in transplantation experiments designed to study radioprotection or immune tolerance.

In 1949 Jacobson et al. (18) made a seminal observation that shielding of the spleen rendered nonlethal a dose of radiation, which administered to the entire body would have been lethal. A subsequent study showed that injection of bone marrow or spleen cells from a nonirradiated donor had the same effect as shielding the spleen (19). While in hindsight the explanation for these results seem obvious, for some time there was debate as to whether this protection was due to some trophic effect or was due to engraftment of cells. It was only in later studies employing chromosome markers that the cellular basis of this radioprotection was firmly established and mice injected with suspensions of hematopoietic cells were shown to recover because their hematopoietic system, including lymph node, thymus, marrow, and spleen were repopulated by adult bone marrow cells and also fetal liver cells $(20,21)$.

The question was then raised as to whether such trafficking and colonization would occur in nonirradiated animals. Harris and Ford (22) had pioneered a system based upon identifiable cytogenetic differences using the T6 chromosome marker system in the mouse and showed by 


\section{LYMPHOID SYSTEM ONTOGENY}

thymic grafting and regrafting experiments that there is a movement of cells from the bloodstream through the thymic graft to the lymph nodes. In adult mouse parabiosis studies, again using the T6 marker, a reciprocal exchange of cells between partners was demonstrated in lymph node, spleen, thymus, and bone marrow, and chimerism persisted after the animals were separated (23). It was significant that while spleen and lymph node chimerism was $40-50 \%$, marrow chimerism was only $5 \%$ at 4-5 weeks and thymus and marrow chimerism only reached a $15-18 \%$ even after 30 weeks of union, suggesting only a low level of immigrant stem cell influx in the adult steady state in these tissues. This important observation was confirmed and extended by studies some $37-39$ years later $(24,25)$ indicating that stem cell homeostasis within the adult marrow is primarily maintained by the retention of stem cells derived from the replication events within the marrow, not the homing and engraftment of stem cells from the circulation. The question remained as to whether vascular interchange of cells between hematopoietic and lymphoid organs occurred during development.

A crucial observation had been made by R.D. Owen in 1945 (26) in his discovery that persistent erythrocytic chimerism occurred among dizygotic twin cattle where placental vascular anastomoses had formed early in their development. This was a seminal observation for our future understanding of tolerance. Moreover, it held profound implications with respect to hematopoiesis. Owen's observations prompted me to conclude that hematopoietic cells readily exchanged via the vasculature during development. Among the hematopoietic cells exchanged, I reasoned, there existed a population that stably generated progeny of all lineages-hematopoietic stem cells. If this interchange was not a phenomenon limited to dizygotic cattle, could it also provide a physiological explanation for lymphoid engraftment reported in radiation chimeras? Against this background, I undertook a series of experiments to investigate the validity of the hypothesis I was developing. Hasek (27) had devised a technique for bringing about a vascular fusion between the chorio-allantoic membranes of two chick embryos that led to mutual tolerance in the chicks after hatching, providing me with an experimental system to evaluate migration streams. By varying the time of onset of establishment of the vascular anastomosis and the time of evaluation of the developing embryos hematopoietic and lymphoid tissue I believed that I could determine with some accuracy the timing of cell migration via the circulation and the role of cell migration, if any, in establishing lymphopoiesis or hematopoiesis from the outset. However, I needed a stable marker for tracking the interchange of cells between the parabiosed embryos. This was provided by John Owen, my thesis advisor, who devised an improved method for preparing avian metaphase chromosome spreads that allowed accurate discrimination of male from female (28). In a series of papers between 1965 and 1967 Dr. Owen and I demonstrated that extensive, durable chimerism resulted if vascular anastomosis was established prior to the onset of hematopoiesis in marrow or spleen, or prior to onset of lymphopoiesis in thymus and bursa of Fabricius $(2,5,14-17,26)$. Significantly, thymic chimerism was not observed if parabiosis was delayed till after the onset of thymic lymphopoiesis, suggesting timed waves of colonization. As initially formulated we proposed that yolk sac blood islands were the primary source of these migratory cells based upon the fact that this was the first site of hematopoiesis and remained a major site of hematopoiesis at the time the primary lymphoid organs were undergoing colonization $(2,4,6-9)$.

Sir MacFarlane Burnet, who had received the Nobel Prize with Peter Medawar for his clonal selection theory of immune development, invited me to be his postdoctoral fellow at the Walter and Eliza Hall Institute of Medicine in Melbourne, which, at the time was the mecca of immunology research and retains a formidable position in immunology and hematology research to this day. After two years, I decided the challenge before me lay not in basic immunology but in the broader field of experimental hematology. At that time the in vitro colony forming cell (CFC) assay that had been developed by Ray Bradley and Don Metcalf in Melbourne (29) provided a quantitative way of measuring an early hematopoietic progenitor. The relationship of the CFCs to the spleen colony forming unit (CFU) discovered by Till and McCulloch in 1961 (30) was, however, unclear. We used the continuous density gradient cell separation system developed by Ken Shortman at the Hall Institute to physically separate CFUs from in vitro CFC (31-33) and proposed a parent-progeny relationship, with the CFUs representing hematopoietic stem cells and the CFC being committed progenitors derived from them. This concept held for many years, until it was determined that the CFUs (at least the great majority of such cells) were not long-term repopulating stem cells (34).

We applied these two assays to determine when in development either cell type originated $(17,35)$. We showed that CFC that had the cytokine responsiveness and differentiation potential of definitive CFU-GM, preceded CFUs in YS but that at later stages of development CFUs and long-term repopulating stem cells appeared in YS, followed by fetal liver, then spleen, and finally marrow. In organ culture of embryo and yolk sac separated at E7.5 we observed extensive erythropoiesis with generation of definitive CFU-GM in the yolk sac itself at levels equivalent to cultures with YS attached to embryo, whereas in embryo alone there was no evidence of hematopoiesis, nor detectable CFC formation in the absence of the yolk sac. We believed that this was evidence that definitive 
hematopoiesis originated in the yolk sac and continued after YS hematopoietic stem/progenitor cells migrated into the embryo. We then showed in a series of grafting and transplantation studies that murine fetal liver was colonized by immigrant cells at E10 at the $\sim 28$ somite stage of development (36). Subsequent studies by DieterlenLievre and associates (37-40) exploited differences in nuclear morphology of the chick and quail embryos to demonstrate, in hybrids, an intraembryonic origin of lymphoid precursors in the para-aortic region of early embryos. Medvisnky et al. (41-43) first provided convincing evidence for the origin of primitive hematopoietic stem cells capable of fully reconstituting the lymphomyeloid system when transplanted into adult mice. These cells arose in the floor of the dorsal aorta in the aorta-gonad-mesonephros (AGM) region of the E10.5 mouse embryo.

The intense debate over the virtues of the yolk sac versus the intraembryonic site as sources of cells that subsequently colonized the later developing lymphoid and hematopoietic tissue has continued to the present day and obscures the significance of the embryonic stem cell migration streams that we defined years ago. The following sections review the current state of knowledge of hematopoietic, lymphoid, and endothelial ontogeny. Since I present my review with a personal bias, I direct interested readers to other reviews in this area that have been published in this Journal in recent years (44-47).

\section{DEVELOPMENT OF THE YOLK SAC}

In the mouse, mesodermal cells destined for extraembryonic sites exit the posterior primitive streak and subdivide the embryo into three separate cavities by the neural plate stage (E7.5). The central cavity, the exocoelom, becomes completely lined with mesoderm and visceral yolk sac (YS) forms where this is adjacent to visceral endoderm. The posterior primitive streak-derived mesoderm receives signals from the visceral endoderm that involve Indian hedgehog, and smoothened (Smo), a receptor component essential for signaling, acting via induction of bone morphogenic protein-4 (BMP-4) in mesoderm, that in turn induces hematopoietic and vascular specification and blood island development (44, 48-50). Vascular endothelial growth factor A (VEGFA) plays a pivotal role in the first step of endothelial and hematopoietic development in the YS and at the onset of gastrulation is expressed in the YS visceral endoderm and mesothelium (51). Its receptors, Flk-1 and Flt-1, are expressed on the hemangioblasts and angioblast and Flt-1 is expressed on the HSC developing in the blood island $(46,52,53)$.

The YS is the site of primitive generation erythropoiesis and macrophage production. The wave of primitive eryth- ropoiesis begins in the mouse YS at E7.5 with nucleated red cells producing embryonic globin predominating in the circulation through E14.5 with eventual replacement by fetal liver-derived red blood cells (RBC) expressing adult globins by E15.5-16.6. The YS is also the first site of definitive multilineage, and myeloid and erythroid-lineage restricted, progenitor cell production $(35,54,55)$. Definitive erythroid (BFU-E) and myeloid (CFU-GM) progenitors and mast cell precursors are detected in the YS at E8 $(35,55)$. They appear not to differentiate locally but most likely migrate to the fetal liver where BFU-E/CFUE initiate definitive erythropoiesis (56). A population of high proliferative potential (HPP) CFC were detected at E8 (1-8 somites), exclusively in the YS, and this remained the main site of expansion ( $>100$-fold) of these multipotent precursors until E10.5-11.5 when there was a dramatic increase of HPP-CFC in the circulation and liver, with a concomitant drop in the YS (55). Upon secondary replating these HPP-CFC exhibited the stem cell features of self-renewal and potential to generate definitive erythroid and macrophage progeny $(45,46)$. Separation of YS and embryo at an early E8 stage, before a common circulation is established, showed that HPP-CFC were found exclusively in the YS, and examination of the blood at E8.5 suggested that they entered the circulation from YS together with the first erythroblasts.

The YS does not contain cells capable of long-term multilineage engraftment of adult irradiated mice until after such cells have appeared in the AGM region at E10.5, but they appear by E11 in the YS and are present till E13 $(35,43,57)$. It has been argued that the AGM region is the sole site of origin of "definitive" HSC capable of engrafting adult recipients, and the presence of these cells in the YS at later stages represents an immigrant population (58-61). However, total body quantitation and tissue distribution analysis of competitive repopulating HSC detected by limiting dilution analysis argues for two independent sources of "definitive" HSC, with both AGM and YS participating in seeding the fetal liver (43). Support for this view was obtained by Matsuoka et al. (62) who generated both CFUs, and HSC that engrafted adult mice, following co-culture of either E8-8.5 YS or intraembryonic splanchnopleuric mesoderm (P-Sp) on a stromal cell line generated from the AGM region.

HSC are defined as cells with multilineage (lymphomyeloid) differentiation potential and extensive selfrenewal potential. By this criteria, the YS contains

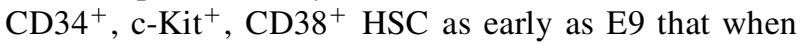
injected directly into the liver of busulphan-conditioned neonatal mice, gave long-term lympho-myeloid reconstitution $(54,55,63)$. Secondary engraftment in sublethally irradiated mice demonstrated that the YS-derived HSC acquired normal marrow homing properties. The first detection, in the AGM region at E10.5, of HSC capable of repopulating adult mice (41-43) does not a priori exclude 
YS HSC in playing a significant role in subsequent hematopoietic development since the only requirement of the initial HSC population is that it be capable of colonizing the liver, which YS-derived HSC clearly can do $(54,55,63)$. Co-culture of YS on AGM stroma has been reported to confer adult engraftment potential (62), suggesting an inducible function for stromal cells in this region, particularly mesenchymal cells on the floor of the dorsal aorta. As currently envisaged, this inductive influence confers HSC potential in locally generated hematopoietic clusters on the floor of the dorsal aorta (vide infra), but it is conceivable that early HSC exiting the YS may traffic into the dorsal aorta and come under the influence of the AGM stroma, and acquires adult engraftment potential. The molecular basis for acquisition of adult engraftment potential may involve upregulation of HOX genes since transduction of HOXB4 into cells isolated from precirculation YS (E8.25) endowed them with long-term lymphomyeloid engraftment capacity in adult irradiated mice (64).

\section{LYMPHOID POTENTIAL OF YS CELLS}

There has been a long, and as yet unresolved debate concerning the role of the YS in generating B cell progenitors. Early studies with Ig allotype markers showed that YS cells transplanted into adult mice generated B cells (65), and in utero injection of E8-10 YS resulted in post-natal B and T chimerism (66). Chromosome marked E11 YS cells were shown to provide long-term lymphoid ( $\mathrm{T}$ and $\mathrm{B}$ ) and myeloid engraftment in mice (35). In a series of studies, Auerbach et al. $(12,13,67,68)$ showed that AA4. $1^{+}$cells from YS as early as E8-E9, when co-cultured on marrow stroma or YS endothelial lines could generate cells with $\mathrm{B}$ and $\mathrm{T}$ potential a measured in vitro and when transferred in vivo into immunodeficient mice.

Cumano et al. (69) initially reported that $\mathrm{AA}^{+}$, Sca- $1^{-}$cells in both yolk sac and embryo at E8.5 were able to generate both $\mathrm{T}$ and B cells in an S17 stromal coculture with IL-7 and c-Kit ligand. In a subsequent study Cumano et al. (70) separately cultured mouse embryo and YS at the presomite, pre-vasculature E7.5-8 stage for 48 hrs and observed B cell differentiation only in the embryo. B lymphoid potential was observed in cultured YS obtained after the circulation was established, favoring their view that the YS is colonized by P-Sp-derived lymphoid progenitors. The absence of definitive hematopoietic progenitors in their cultured YS, yet their presence in the YS in situ, suggests that the culture conditions were deficient for maintenance of a normal pattern of lymphohematopoiesis, rendering a negative result inconclusive. Ogawa et al. (71) reported B cell progenitors developing in cultures of E9.5 embryos but not of YS, although excessive production of mast cells in the latter cultures may have inhibited lymphoid differentiation. Nishikawa et al. (72) isolated VE-cadherin ${ }^{+}, \mathrm{CD} 45^{-\mathrm{ve}}$ "endothelial" cells from E8.5-9.5 embryo and YS and showed B cell differentiation from both sources on OP9 stroma in the presence of IL-7, an important early B cell growth factor.

These variable and often conflicting data can be attributed, in part, to culture variables such as whole tissue cultures versus dispersed cells, the use of different stromal lines, and particularly the use of supplemental cytokines such as IL-7 and c-Kit ligand. Certain of these conditions may provide an environment capable of supporting lymphoid differentiation from "hemogenic" endothelium or hemangioblasts; others may support differentiation from lymphomyeloid stem cells and pMix; while others can expand only those cells that have undergone B cell commitment ( $\mathrm{pB}$ or $\mathrm{pB} /$ macrophage). By restricting the criteria for a committed $\mathrm{B}$ cell progenitor to cells expressing CD45, and probably CD19, IL7R $\alpha$ and c-Kit, these cells first appear within the E10 AGM region where they may traffic to the YS as well as the early liver. It is probable that more primitive cell populations in the YS can migrate into the embryo and undergo $\mathrm{pB}$ commitment in the AGM region or early liver.

\section{DEVELOPMENT OF HEMATOPOIESIS IN THE AORTA-GONAD MESONEPHROS REGION}

In the human embryo, hematopoietic clusters of CD34+ cells appear in the aorta at 27 days gestation, 8-9 days after initiation of YS hematopoietic, and 6 days after the onset of the circulation (Fig. 1) $(58,59,73)$. Ultrastructural studies show that the endothelial basal lamina is intact where it interacts with the cells in the hematopoietic clusters, and the hematopoietic and endothelial cells are interconnected by tight junctions $(74,75)$. The precursors of the hematopoietic clusters in the periaortic region were considered "endothelial" based on expression of CD34 and CD31 (PECAM-1), Ulex Europu lectin binding, uptake of acetylated low-density lipoprotein (Dil-Ac-LDL), and absence of CD45 (45-47,71). This blood-forming "endothelium" is present in the human embryo AGM region at 28 days with a peak frequency at 31 days and absence by 44 days (76). Culture of the para-aortic splanchnopleura (PSp) from 21-26 day human embryos on marrow stromal cells generated hematopoietic cells, demonstrating the hematogenic potential of P-Sp mesoderm that precedes the appearance of "hemogenic endothelium" (59). The pre "endothelial" mesodermal precursor is $\mathrm{CD} 34^{-\mathrm{ve}}$, CD45-ve (20), and VEGFR-2/KDR ${ }^{+}$(77).

In mice, hematopoietic clusters appear at E10.5 in the ventral floor of the dorsal aorta. They appear to be in direct contact with underlying mesenchyme where the en- 


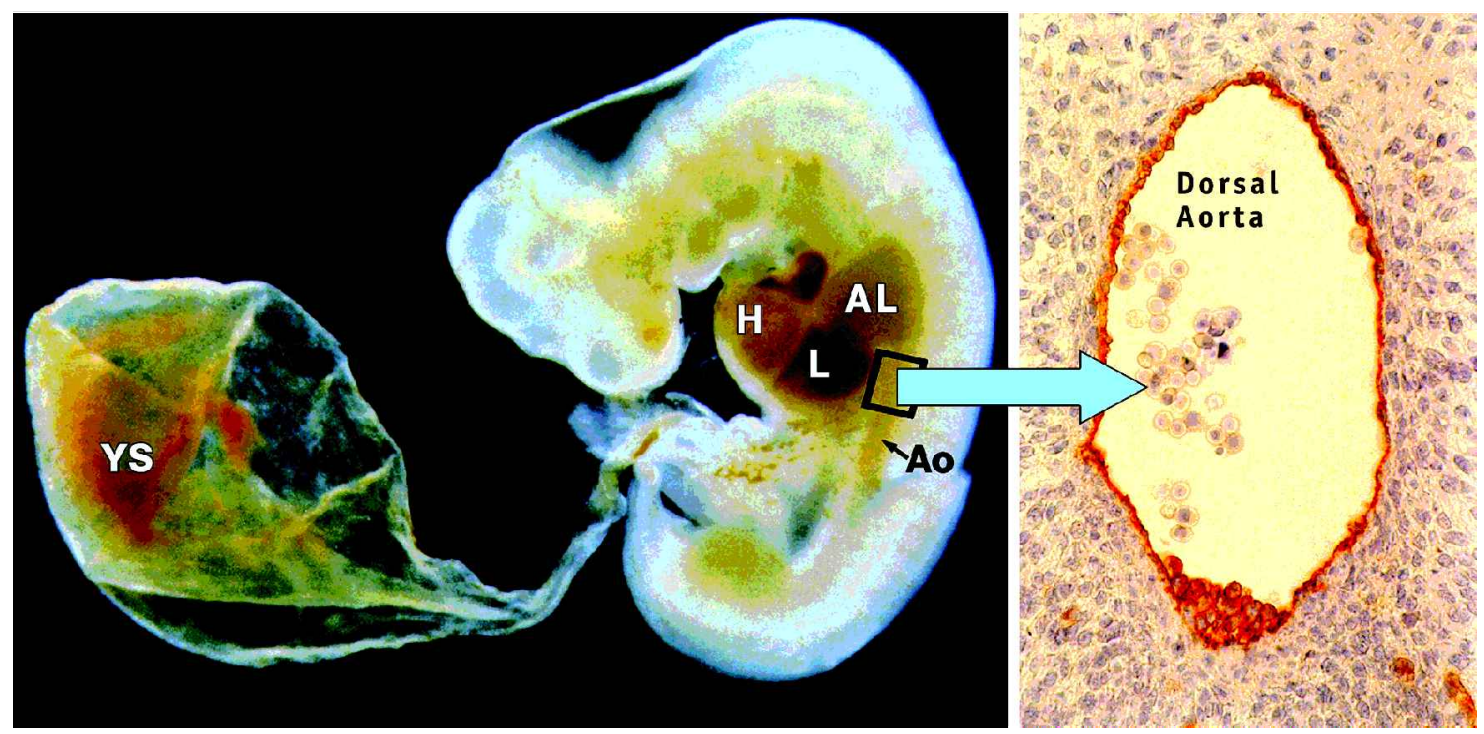

FIG. 1. Photograph of a 5-week-old human embryo. Ao, dorsal aorta; AL, anterior limb rudiment; L, liver; H, heart; YS, yolk sac. Enlarged view of the dorsal aorta from the same embryo immunostained for CD34 expression, showing CD34+ endothelium and the ventral thickening of the vessel wall resulting from accumulation of rounded CD34+ hematopoietic cells that are also CD45 +. Nucleated erythrocytes are present in the lumen. Photo courtesy of Dr. Bruno Péault. From Tavian M, L Coulombel, D Luton, HS Clemente, F Dieterlen-Lievre, and B Péault. (1996). Aorta-associated CD34 ${ }^{+}$hematopoietic cells in the early human embryo. Blood 87:67-72. Copyright ${ }^{\odot}$ American Society of Hematology, reproduced with permission (73).

dothelium is interrupted. VE-cadherin-expressing cells in the AGM have hematopoietic potential, and VE-cadherin is expressed on the luminal aspect of vascular endothelium but not in $\mathrm{CD} 45^{+}$aorta-associated hematopoietic clusters $(45,72,76,78)$. A discrete region of densely packed mesenchymal cells lies beneath ventral floor of the dorsal aorta and is 3-4 layers thick in mouse and 5-7 layers in human $(58,74,75)$. These mesenchymal cells are interconnected by tight junctions, express smooth muscle $\alpha$-actin ( $\operatorname{SM} \alpha$ A), and may be precursor of vascular smooth muscle. BMP-4 is polarized to the ventral wall of the dorsal aorta in the mesenchymal layer underlying the intra-aortic hematopoietic clusters where it could induce P-Sp mesoderm to become hemangioblasts and HSC (79). Medivinsky et al. (41) identified the mouse AGM region at E10.5 as a source of CFU-S, preceding their appearance in YS. CFUs precursors were present in both AGM and YS by E9 since cultures of either tissue at this stage generated CFU-S (42). In vivo engraftment was obtained with cells from the E10.5 dorsal aorta and vitelline/umbilical artery $(80,81)$. Quantitation of long-term repopulating stem cell numbers by limiting dilution assay has shown that they first appear in the $\mathrm{AGM}$ at E10.5 and are present in equal numbers in AGM, YS, circulation, and early liver rudiment by E11 (43). HSC capable of long-term lymphomyeloid engraftment could be generated in organ culture of $\mathrm{P}-\mathrm{Sp}$ isolated prior to the onset of the circulation (E7.5-8), whereas cultured YS failed to generate such HSC (61). However, Matsuoka et al. (62) were able to generate repopulating HSC in co-culture of equally early P-Sp and YS with a stromal line (AGM-S3) derived from the E10.5 AGM region. This line may have some unique properties since in a study of 100 stromal lines generated from AGM subregions, most were supportive of adult HSC expansion but none were able to induce development of engraftment HSC when co-cultured with CD34 ${ }^{+}$ $\mathrm{cKit}^{+}$cells from E10 AGM or YS (82).

The various inductive influence of the subaortic mesenchyme could cause bipotential precursors located in the floor of the aorta to preferentially adopt a hematopoietic fate. Alternatively, endothelial cells may de-differentiate and switch to a hematopoietic fate in response to local or transient signals. A third possibility is that hemangioblasts or their precursors may migrate secondarily into the aortic wall, either from the underlying mesenchyme or from the circulation, in response to a chemokine gradient. Endothelial cells, angioblasts, and HSC express CXCR4, and mesenchyme adjacent to the dorsal aorta expresses high levels of its ligand SDF-1, indicating a role for this chemokine pathway in both vasculogenesis and migration of hemangioblastic precursors to the floor of the aorta (83).

The Runxl/AML1 gene plays a critical role in establishment of definitive hematopoiesis in the AGM. Runxl expression is initiated in mesenchymal cells at the distal tip of the allantois, and endothelial cells in ventral portion of paired dorsal aorta at E8.5 and in both endothelium and mesenchyme of the ventral AGM and in the intra-aortic hematopoietic clusters between E9.5-11.5 (84). In Runx1/LacZ mice, some $30 \%$ of the cells recovered from the AGM and the vitelline and umbilical arteries at E11.5 were Runx 1/LacZ ${ }^{+}$, and this population contained 
all HSC capable of engrafting irradiated recipients (84). These HSC were initially CD $45^{-\mathrm{ve}}$ at E10.5, but by E11.5, HSC activity was present in both $\mathrm{CD} 45^{+}$and CD45-ve fractions. The vast majority of HSC was $\mathrm{CD}_{4} 1^{+}(85)$ and were found in both the positive and negative fraction of AGM stained with CD31, Flk-1, or VEcadherin (84). The expression of Flk-1 on these HSC populations is controversial, with some studies showing expression of the receptor in the hematopoietic clusters (86), others showing that it is barely detectable in hematopoietic clusters but is expressed on hemangioblastic precursors (77), or providing data suggesting that some HSC that lack Flk-1 did engraft indicating downregulation of Flk-1 on CD45 ${ }^{+}$intra-aortic clusters (84).

In Runx1-deficient mice, HSC and intra-aortic clusters were absent, while in Runxl hemizygous mice, hematopoietic clusters were reduced in number and size and HSC numbers and distribution were altered, indicating a gene dosage effect (84). Haploinsufficiency of Runxl results in an earlier appearance of engraftable HSC in the YS with E10 YS cells now capable of reconstituting the hematopoietic system of irradiated adult mice (87). At the same time there is premature termination of HSC activity in the AGM explants consistent with a change in the balance of HSC emergence, migration, and/or maintenance. With hemizygous levels of Runx the YS may autonomously generate HSC simultaneous to their generation of HSC in the AGM; alternatively AGM may autonomously generate abundant HSC that immediately and rapidly migrate to the YS where they are detected in abundance, or Runxl insufficiency blocks emigration of HSC from the YS resulting in accumulation there and a deficiency in the AGM.

In birds at E2 the aortic endothelium consisted entirely of $\mathrm{CD} 45^{-\mathrm{ve}}$, VEGFR-2 ${ }^{+}$flat endothelial cells. The first intraembryonic hematopoiesis occurs at E3 in endothelium-associated intra-aortic clusters of markedly basophilic cells with prominent nucleoli. CD $45^{+}$VEGFR-2 ${ }^{-v e}$ hematopoietic progenitors are detected in the aortic wall at E3-4 (88). Subsequently (E6-8) hematopoiesis occurs in diffuse hematopoietic "para-aortic foci" located in the dorsal mesentery ventral to the aorta $(89,90)$. Marker studies showed that the intra-aortic clusters developed in situ and not by migration from the YS (91). Acetylated low-density lipoprotein (Dil-Ac-LDL) labeling indicated that the hematopoietic clusters originated from aortic endothelium, while retroviral vector marking indicated that the para-aortic foci were derived from intraaortic clusters $(89,90)$. Mesodermal subdivision transplantation showed that the endothelium of floor of the dorsal aorta develops from splanchnopleural mesoderm and generates progenitors with dual hematopoietic and angiogenic potential, while endothelium of the aortic roof and sides arise from somite mesoderm that generates "pure" angioblasts (89).

\section{THE ONTOGENY OF ENDOTHELIUM AND THE HEMANGIOBLASTIC OR HEMOGENIC ENDOTHELIAL ORIGIN OF HEMATOPOIESIS}

Vascular development is initially asymmetric, centered in YS blood islands, and in the embryo proper where angioblasts begin to coalesce into the aorta. Morphogenesis of blood vessels is marked by a sequential pattern of gene expression in which SCL and Flk1 are expressed first at the angioblast stage, followed by PECAM, CD34, VE-cadherin, and later Tie2, while SCL expression is downregulated in endothelium of mature vessels (92). By the murine 3 somite stage, vascular development has spread through the YS, and extended aortic tubes are visible (93). Beginning at the 4 somite stage, erythroblasts disperse through the distal yolk sac and a few erythroblasts appear in the head and tail region of the embryo where the embryonic and YS vasculature meet. The circulation onset is defined as erythroblast movement within vessels and is initiated at the murine 4-6 somite stage during E8.25.

The respective roles of hemangioblasts as common precursors of endothelium and hematopoiesis versus the plasticity of "hemogenic endothelium" in initiating hematopoiesis in the AGM or YS is debated (45,46,74-76, $79,90,94)$. This is not simply a semantic issue since the hemangioblast concept recognizes a common undifferentiated precursor, whereas the "hemogenic" endothelium concept recognizes that an endothelial pathway of differentiation has occurred but the cells remain sufficiently plastic to be capable of redifferentiating to hematopoietic lineage. A number of these studies identify endothelium as the source of hematopoiesis based upon isolation of cells expressing markers associated with endothelium (VE-cadherin, CD31/PECAM, Flk-1, Flt-1, Tie-2, Ulex Europus agglutinin binding, Dil-Ac-LDL uptake). None of these markers is unique to endothelium and possibly could be expressed on hemangioblasts or pre-hematopoietic mesoderm, while some are expressed on HSC or more differentiated myeloid cells. Direct derivation of hematopoietic cells from mature, already differentiated, endothelium has been reported in Ac-LDL-DiI labeling studies $(89,90,95)$. Following intra-cardiac injection of E10 mouse embryos with Ac-LDL-DiI, staining was found within $1 \mathrm{hr}$ and was confined to $\mathrm{CD} 31^{+}, \mathrm{CD} 34^{+}$, CD $45^{-v e}$ endothelium along the entire vascular tree (95). At twelve hours after injection, $1.4 \%$ of circulating cells were $\mathrm{DiI}^{+}$, and of these, $43 \%$ expressed the erythryoid marker Ter 119 and adult globin, characteristic of definitive definitive erythropoiesis. The rest of the $\mathrm{DiI}^{+}$cells represent committed white blood cells, lineage restricted and multi-potent progenitors as revealed by colony formation, and HSC. The remarkable feature of this observation is the rapidity with which the endothelium differ- 
entiates to multipotent HSC, and lineage restricted erythroid progenitors (BFU-e) that in turn differentiate to the extent that they express globin genes, maturation steps that normally require at least $4-6$ cell divisions. It is also likely that the transition from hemangioblast to endothelium or HSC is not abrupt, but is a progressive process of increasing restriction. A cautionary note in various marker studies involving endothelial and hematopoietic cells is provided in co-culture experiments with CD34+ cells and tumor necrosis factor- $\alpha(\mathrm{TNF} \alpha)$-treated endothelium, where we observed, by confocal microscopy, a bi-directional transfer of an intact marker protein (Green Fluorescent Protein) between developing dendritic cells and endothelium (96). This interchange was facilitated by the intimate interaction, observed in ultrastructural analysis, between the myeloid dendritic cells which can be partially "internalized" by TNF-stimulated endothelium with the membranes of both cell types remaining intact. This may represent emperipoiesis, a form of transmigration of one cell type through another. A further caveat is that most of the markers that have been considered endothelial-specific can be expressed on hematopoietic cells. Certain monocyte-macrophage-derived cells have proangiogenic effects due to secretion of angiogenic growth factors and express endothelial-associated features (CD31, incorporation of Dil-acLDL, binding of Ulex europus agglutinin), yet still express macrophage features of CD45 and CD14 expression (96). These cells may be comparable to a CD45+, CD11b+, Sca$1+$, Tie- $2+$ partially CD34+ hematopoietic population that is also reported to home to sites of neoangiogenesis and closely interact with vascular endothelial cells (97).

Evidence for the existence of hemangioblasts has come from studies on embryonic stem cells. Culture of embryonic stem cell-derived embryoid bodies with vascular endothelial growth factor (VEGF) and cKit ligand led to development of colonies of blast cells (CFU-Bl) which upon secondary replating generated colonies of both primitive generation of erythroid as well as definitive generation erythroid and myeloid lineage, supporting the view that both definitive and primitive generation can arise from a common precursor (98). However, murine ES cells that have Runxl homozygously deleted can form hemangioblasts that produce primitive but not definitive hematopoietic cells (99). In addition, blast colonies can be shown to generate endothelium, supporting the view that CFU-B1 are hemangioblasts (100). The thrombopoietin (Tpo) receptor c-Mpl can be detected by day 3 of embryoid body formation when hemangioblasts first arise and Tpo alone supported CFU-Bl formation and nearly doubled the number of blast colonies generated when combined with VEGF and c-Kit ligand (101). A more primitive embryoid bodyderived VEGF-independent type of colony forming cell was subsequently described, the transitional CFC (102) or pre-blast CFC (103). This type of colony contains cell population undergoing commitment of mesoderm to hematopoietic and endothelial lineages, and cardiomyocytes (102). Individual transitional colonies express a combination of mesoderm, hematopoietic, and endothelial genes (Brachyury, flk-1, SCL/tal-1, GATA-1).

Kumano et al. (104) showed hematopoiesis and angiogenesis was severely impaired in E9.5 P-Sp organ cultures established from Notch1-deficient embryos. P-Sp and YS cells from Notch $1+/+$ and $+/-$ but not from Notch $-/-$ embryos showed hematopoietic engraftment in busulfan-conditioned newborn mice. Studies with conditional Notch1 deficient BM showed normal hematopoietic engraftment; thus Notch1 acts at the stage of HSC and angioblast generation from hemangioblast in both P-Sp and YS but is not required for expansion or maintenance of HSC (104).

A homeobox gene termed Hex has been shown essential for hemangioblast differentiation, and studies of Hex-1- embyonic stem (ES) cells and embryos has shown marked defects in definitive hematopoietic progenitor production in YS, and embryoid bodies showed defective endothelial and definitive hematopoietic development (105).

The zebrafish mutation kugelig is associated with severe anemia, reduced expression of $S C L$, and total absence of $A M L 1 /$ Runxl in blood cells but with normal numbers of $F l k 1+$ angioblasts and normal vascular development (106). The mutation is in $C d x 4$, a member of the caudal family of homeobox genes that are thought to regulate Hox gene expression. A late primitive streak stage $S d x 4$ is confined to mesodermal cells of posterior embryo, the allantois, and the YS wall. Results suggest that if hemangioblasts exist in vivo then they must arise before the onset of $S C L$ expression, and that $C d x 4$ is necessary for this population to differentiate into an $S C L+$ hematopoietic precursor. Alternatively the blood and vascular lineages may arise independently from posterior mesoderm, with $C d x 4$ being required solely for specification of hematopoietic fate. Finding that $S c l$ over-expression fails to rescue blood development suggests that the pathway acts to make lateral plate mesoderm competent to respond to genes that specify hematopoietic fate (106). Transduction of $C d x 4$ into embryoid body cells induced a marked enhancement of hematopoietic differentiation associated with upregulation of Hox genes (HoxB3, HoxB8, HoxA9, and particularly HoxB4) that are implicated in HSC or progenitor cell proliferation.

\section{DEVELOPMENT OF THE THYMUS}

The thymus develops from the endoderm of the third pharyngeal pouch with subsequent epithelial-mesenchy- 
mal interactions and Notch signaling participating in thymic organogenesis $(2,107)$. Between E11-E12 in the mouse, the stratified epithelium undergoes morphological changes, beginning to express high levels of MHC II + and of Delta1, the Notch ligand that plays a critical role in T cell development (107) (Fig. 2). Comparable development of the thymic rudiment is seen at embryonic day $\sim 35$ days in human, 7-8 days in the chick embryo, and day 4 in Xenopus. Our studies in parabiotic chick embryos demonstrated very high levels of thymic lymphoid chimerism following establishment of a yolk sac vascular union at d6-7 of incubation but not following a later vascular union $(2,14)$. We proposed that the thymic immigrant cells were derived from the yolk sac $(2,16)$, a view supported by studies in which 7-day yolk sac cells were injected into irradiated chick embryos and colonized the thymus $(15,39)$, and by studies on the thymic homing and differentiation of tritiated thymidine- labeled yolk sac cells (Fig. 3) (17). However sex mismatched YS and embryo chimeras generated at 33-55 hrs of incubation showed that the thymus was populated by cells of the sex of the embryo and not by YS (16). Studies in chick-quail chimeras also showed that the primary lymphoid organs were colonized by cells that originate in the para-aortic region $(39,40)$. Coltey et al. (108) proposed that the avian thymus is colonized by three waves of immigrant cells, the first wave came from para-aortic foci at d6, with subsequent waves at day 12 and day 18 originating from marrow and spleen. These opposing views can be reconciled if the yolk sac is colonized at a very early stage by cells originating in the para-aortic region, and like the mammalian fetal liver, may then serve as a site for expansion of lymphoid progenitors that secondarily migrate to the thymus. In Xenopus embryos, diploid ventral blood islands (VBI), analogous to the yolk sac, and the dorsal stem cell compartment (DSC) analo-
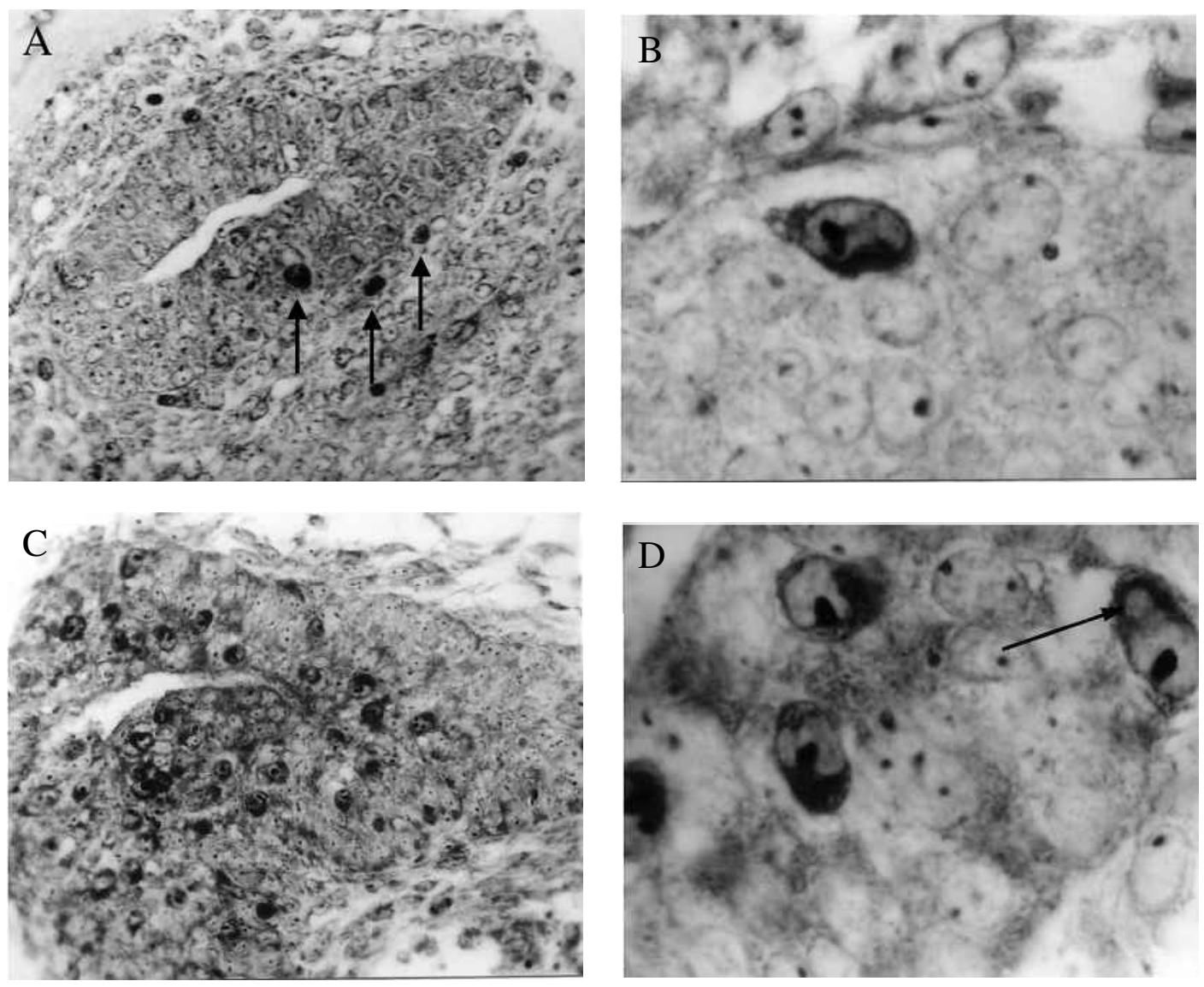

FIG. 2. A. E11 mouse embryo thymic rudiment. At this stage the rudiment is composed of pale-staining epithelial cells with a central lumen, a remnant of the pharyngeal pouch. Candidate immigrant cells with deeply staining basophilic cytoplasm and prominent nucleoi (arrowed) are present within the epithelium and adjacent to it. Giemsa stain. $\times 450$. B. Basophilic blast cell in 11 day thymic rudiment. $\times 1000$. C. E12 mouse thymic rudiment with numerous large basophilic cells within the circumscribed epithelial rudiment at a stage prior to penetration of the epithelium by vasculature. $\times 450$. D. Basophilic cells in E12 thymus. Note the deeply stained cytoplasm, prominent nucleoli and Golgi apparatus (arrowed). $\times 1000$. 


\section{MOORE}
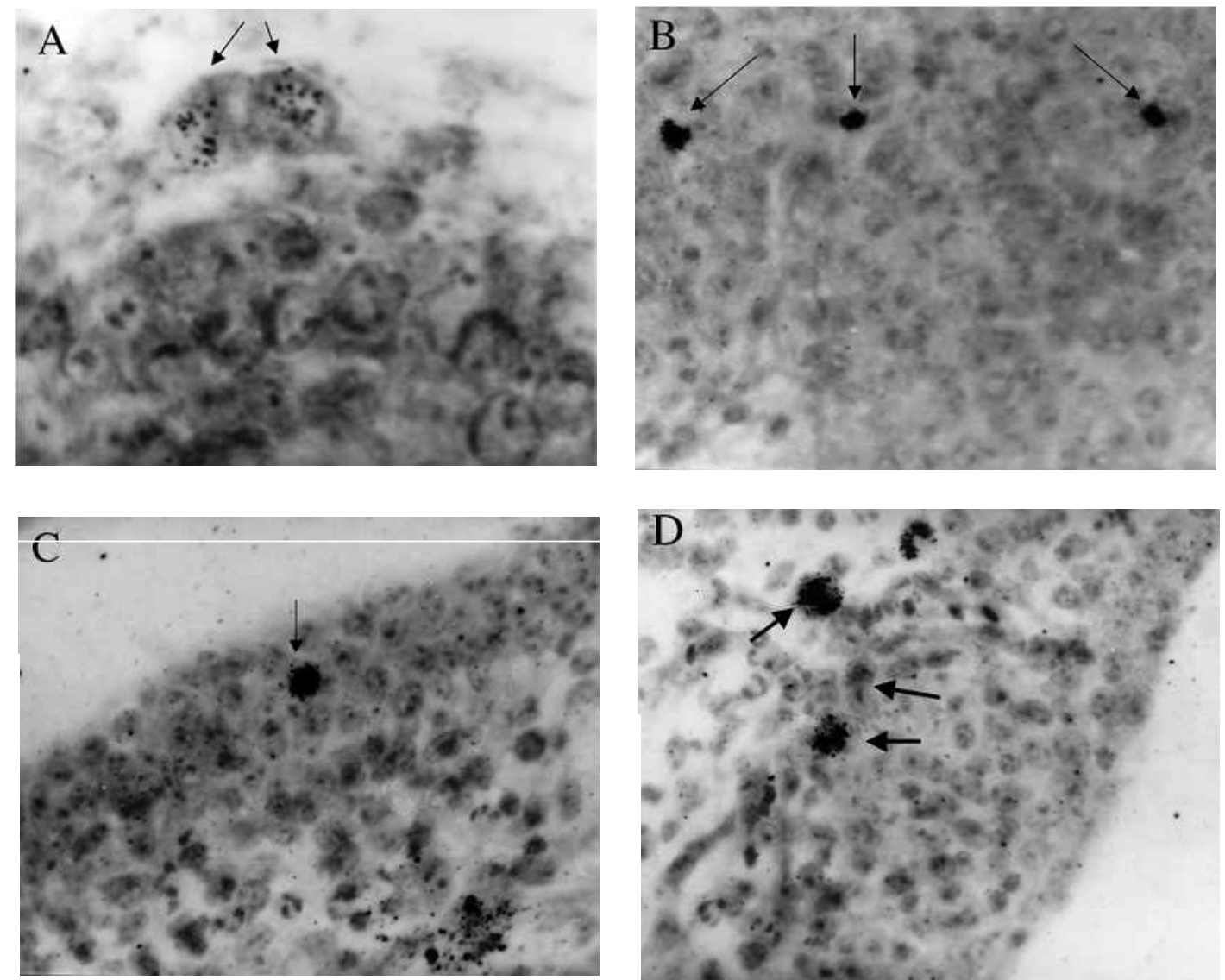

FIG. 3. Tritiated thymidine-labeled avian embryonic yolk sac (E7), embryonic blood (E13), embryonic spleen (E14), or embryonic marrow (E18) cells were injected intravenously into 8-14 day chick embryos. All these sources showed homing of labeled cells to the E8-9 thymus and E14 bursa of Fabricius. Comparably labeled embryonic thymus or bursal cells did not home to these sites. A. Autoradiograph of a section of the E9 thymus $24 \mathrm{hrs}$ after injection showing a pair of labeled cells (arrowed) (probably daughter cells of a cell division) in the perithymic mesenchyme adjacent to the epithelium. $\mathrm{H} \& \mathrm{E}$ stain $\times 1000$. B. Autoradiograph of a section of the E9 thymus $24 \mathrm{hrs}$ after injection showing heavily labeled basophilic blast cells (arrowed) within the thymic epithelium. H\&E stained. $\times 450$. C. Autoradiograph of section of the E15 bursa 24 hrs after injection showing a labeled cell (arrowed) in the epithelium at a very early stage of bud formation. H\&E stained. $\times 450$. D. Autoradiograph of section of the E15 bursa $24 \mathrm{hrs}$ after injection showing labeled blast cells (arrowed) within and adjacent to an epithelial bud. H\&E stained. $\times 450$.

gous to the para-aortic and dorsal aortic region of birds, were transplanted into triploid hosts. Cells from both sources entered the thymus at day 4 post-fertilization and contributed to thymocyte populations from the earliest developmental stage examined (9). Both VBI and DSCderived cells persisted after metamorphosis and contributed to all lymphohematopoietic populations of the adult frog. In synchorial heterozygotic twin marmosets there is extensive thymic as well as bone marrow chimerism identified by sex chromosome analysis (21), supporting the concept that colonization of the developing thymus by immigrant cells occurs in all vertebrate species.

Initial colonization of the thymic rudiment precedes the onset of intrathymic vascularization by two days and is marked by accumulation of basophilic blast cells in perithymic mesenchymal capillaries, followed by their egress and migration into contact with the epithelial anlage. Cytoplasmic extensions penetrate the epithelium basement membrane, and blast cells move into the epithelium and commence proliferation (Fig. 2). Intravenous injection of day 7 yolk sac cells labeled with tritiated thymidine into day-7 chick embryos show a comparable homing to thymic epithelium (Fig. 3). In the Nude mouse, lymphoid precursors fail to enter the epithelium from the perithymic mesenchyme, and the defect, which is in epithelial development, has been attributed to a loss-of-function mutation in the Foxn1 transcription factor (109). MHC class II + epithelial cells are a source of chemoattractant factors, and alymphoid thymic lobes can be shown to attract cells from fetal liver fragments (110).

While thymic epithelium plays an important role in $\mathrm{T}$ 
cell development, less attention has been given to thymic mesenchyme. Mesenchyme surrounding the thymus is derived from cells that migrate from the cephalic region of the neural crest. The importance of this mesenchyme is demonstrated in studies in which E12 thymic lobes were cultured in the presence or absence of perithymic mesenchyme with the former generating all $\mathrm{T}$ cell subsets in vitro, whereas the latter showed severely compromised lymphopoiesis (26). Earlier studies had suggested that the mesenchyme influenced thymic epithelial morphogenesis and the effects on lymphopoiesis were secondary to a defective epithelium; however, there is clear evidence that mesenchymal cells directly affect lymphopoiesis (111). Mesenchymal cells migrate into the epithelial thymus and establish an intrathymic network of fibroblasts with an associated extracellular matrix (ECM). ECM components such as fibronectin and laminin interact with integrins expressed on developing thymocytes, initiating outside-in signaling, and sulfated glycosaminoglycans in the matrix can bind cytokines and chemokines which may be presented to thymocytes. Members of the BM and fibroblast growth factor (FGF) family of growth factors have been implicated in cross talk between stromal cells and the thymocyte compartment $(112,113)$. Impaired thymic development is seen in mice lacking either FGF10 or its receptor FGFR2IIIb (112). The ligands for this receptor (FGF7 and FGF10) are synthesized by thymic mesenchyme, while the receptor is expressed on thymic epithelium. BMP4 acts upstream of FGF7/FGF10, to upregulate Foxn1, leading in turn to upregulation of FGFR2IIIb on epithelium (113). BMP4 also upregulated the stromal chemokines eotaxin and EB-11 ligand (ELC), in an FGF signal-dependent manner (113). Using thymic organ culture, both BMP4 and FGF7/FGF10 arrested early T cell development at the CD4-CD8-CD25$\mathrm{CD}_{4}{ }^{+}$(DN1) stage and at the CD4-CD8- double negative (DN) to CD4+CD8 + double-positive (DP) transition in a stromal compartment-dependent manner (113).

\section{ARE THYMIC COLONIZING CELLS LYMPHOMYELOID STEM CELLS (HSC), COMMON LYMPHOID PROGENITORS (CLP) OR T LINEAGE-RESTRICTED PROGENITORS (PT)}

Limiting dilution in vitro and in vivo thymic lobe colonizing assays have been used to identify thymic repopulating cells and can be used in parallel with $\mathrm{B}$ cell precursor assays in stromal co-culture, myeloid progenitor colony assays, or HSC detected by competitive long-term repopulating assays. Lymphoid commitment has been reported to precede thymic development in the $\mathrm{CD} 45+\mathrm{cKit}+\mathrm{CD} 34+$ hematopoietic clusters of the vascular endothelium of the AGM region (72, 114-118).
In addition to multilineage progenitors, progenitors restricted to T lineage (pT) or T, NK and macrophage lineages (pTM), or B and B plus macrophage lineage (pBM) were identified at this early stage. The common lymphoid progenitor (CLP), identified in adult mouse marrow as a precursor of both $\mathrm{B}$ and $\mathrm{T}$ lineage and possibly involved in colonization of the post-natal thymus (119), does not exist in the embryo (114,120-122). The AGM pT cells have TCR rearrangements and are subsequently found in the circulation and fetal liver at E11-12, coinciding with thymic colonization (122). In the mouse embryo $\sim 20 \mathrm{~T}$ cell precursors enter the thymus at E11-12, increasing to a maximum of $\sim 3,000$ entering between E13-14 (123). This is compatible with the number of CD45+ cells in each E12 thymus lobe ( $~ 50$ cells) (124), and the 100-200 large basophilic cells within the epithelium and the 90-100 in the perithymic mesenchyme reported between E12-E13 (17). At the time of entry into the thymic epithelium at E12, the immigrant cells express CD45+, c-kit,$+ \mathrm{CD} 44+, \mathrm{CD} 34+$ and the $\alpha_{4}$ integrin, but are negative for CD62L, CD25 and Thy-1.2 (124). CD34 is downregulated on thymic precursors between $24-48 \mathrm{hrs}$ after entry and so is a marker for the earliest thymic stem cell in the embryo. The CD45+ migrant stem cells can still be seen in the mesenchyme surrounding the epithelium at E13, suggesting the first wave of stem cells is still entering, but by E14, stem cells are no longer seen in the perithymic connective tissue (124).

It is possible to isolate thymic immigrant cells from the perithymic mesenchyme that have exited the circulation, but prior to their exposure to epithelial inductive influences. These cells are IL7R $\alpha+$ and do not yet express Notch target genes such as Hes-1 and pre-T $\alpha$, but upon entry into the thymic epithelium and exposure to Notch ligands Delta and Jagged, Notch signaling is activated (125). Ectopic expression of Delta ligand on a marrow stromal line, in the presence of IL7 ligand and cKit ligand reproduced a thymic inducing environment that supported differentiation of fetal liver Sca- $1^{\text {hi }}$ c-Kit ${ }^{\text {hi }}$ CD24 ${ }^{\text {lo }}$ Lin-progenitors to functionally mature CD4 and CD8 T cells (126). IL7R $\alpha$ appears to be downregulated on the earliest $\mathrm{T}$ lineage progenitor within the thymus associated with loss of thymic homing capacity (127). Mouse IL7R $\alpha$ chain mutants show profound defects in thymopoiesis in the adult, but fetal thymopoisis is relatively intact, suggesting possible alternate cytokine pathways can operate during ontogeny (128).

The first 14 days of thymic development in the mouse can be separated into four phenotypically and genetically distinct phases (129). The first stage (lineage double negative stage 1) is CD4-CD8-CD25-CD44hi and initially $\mathrm{CD} 34+$ gives rise to $\mathrm{T}, \mathrm{B}$, dendritic cell (DC) and NK; the second stage is CD4-CD8-CD25+CD44 ${ }^{\text {hi }} \mathrm{T}$ or DC only. Stage 3 are CD4-C8-CD25+CD44 ${ }^{\text {lo }}$ and absolutely committed to $\mathrm{T}$. The final stage is pre-CD4+CD8+CD25. 
A 4000-fold expansion occurs in the first 3 phases and a 250 -fold expansion in the early pre-double positive stage.

\section{DEVELOPMENT OF B LYMPHOCYTES IN THE AVIAN BURSA OF FABRICIUS}

B lymphopoisis is initiated in avian species in the bursa of Fabricius - an organ uniquely specialized for this purpose. The search for the mammalian equivalent of the bursa has led to various sites as being proposed as "bursal equivalent," even the appendix, but it is most likely that mammalian B lymphopoiesis occurs in the fetal liver before moving to the bone marrow. The bursal primordium appears by E5 as an epithelial thickening at the ventrocaudal contact of the cloaca with external ectodermal epithelium. By E10-11 longitudinal folds of lining epithelium project into the lumen, and by E12-13 epithelial buds project into the underlying mesenchyme (Fig. 4). Studies in parabiosed embryos and embryonic grafts of bursal rudiments demonstrated that the bursa was colonized by circulating lymphoid precursors that entered at E13-14 (5, 14,15). At this stage large basophilic blast cells are observed in the blood vessels of the mesenchyme adjacent to the epithelial buds. After exiting the vessels the blast cells migrate into contact with the epithelial buds before transiting through the epithelial basement membrane (Fig. 4) and localizing within the epithelium follicle where they proliferate extensively, differentiating into typical bursal B lymphocytes $(5,17)$. Injection of embryos at E10-14 with tritiated thymidine-labeled embryonic yolk sac, spleen marrow, and blood cells (but not thymocytes) showed rapid localization of labeled basophilic cells in the bursal epithelium with subsequent proliferation and lymphoid differentiation (Fig. 3). Chromosome marker studies showed that injection of the same embryonic hematopoietic tissues, but not embryonic thymus, into E14 irradiated embryos confirmed their ability to reconstitute bursal lymphopoiesis (15). Cells present in the E14 spleen or marrow that colonized the bursa upon injection were already $\mathrm{B}$ committed with $\mathrm{VJ}$ recombination, and distinct from $\mathrm{T}$ lineage precursors (130). The precise site of B cell commitment is not known, but marker studies indicate that the B precursors ultimately derive from the intraembryonic para-aortic region, possibly as early as E2 $(39,40)$, although their subsequent expansion and B commitment may occur within the yolk sac and then spleen.

\section{THE MAMMALIAN LIVER AS THE MAJOR SITE OF FETAL HEMATOPOIESIS AND B CELL DEVELOPMENT}

The liver develops from ventral foregut endoderm that is induced to proliferate and adopt a hepatic fate by sig- nals from pericardium and septum transversum mesenchyme (131). In studies involving grafting of fetal liver beneath the adult mouse kidney capsule we showed that autonomous hematopoiesis occurred if the graft was from embryos older than 28 somites (E10), whereas grafts of earlier stages did not show hematopoiesis (36). Injection of hematopoietic cells intravenously into irradiated, fetal liver-engrafted mice showed that the pre- 28 somite graft could support hematopoiesis. This study established E9.5-10 as the time of initial colonization of the fetal liver by immigrant stem/progenitor cells. Limiting dilution long-term repopulation assays demonstrate at least one competitive repopulating unit (CRU) in the liver, circulation, AGM region, and YS at E11, with an increase in the liver of $>50$-fold by E12 and $>250$-fold at E13 (43). After correcting for in vivo seeding efficiency $(\sim 10 \%)$ the data suggests an initial homing of 10 stem cells at E10-11. The $>250$-fold expansion of stem cells in the ensuing $48 \mathrm{hrs}$ is matched by a daily logarithmic increase in CFU-GM BFU-E and CFU-S between E10-13 (17,35). It is likely that continual immigration of stem and progenitor cells occurs with initial colonization from the AGM, but at E12 the YS is making a significant contribution (43). Large numbers of CFU-E appear simultaneously with BFU-E at the onset of hepatic hematopoiesis, and embryonic blood contains significant numbers of definitive hematopoietic progenitors immediately prior to liver development indicating colonization by immigrant progenitors in addition to stem cells (56). A derivation from YS is suggested by studies in human fetuses showing that BFU-E numbers drop abruptly in the YS at 35 days and simultaneously appear in the liver, reflecting oriented migration (47). Thus the liver appears to be colonized by two waves of HSC, the initial one from the AGM arriving at E10, reaching a maximum at E11 and disappearing by E13, and a second wave arriving from the YS on E12. Both these waves are accompanied by immigration of multipotent and unipotent progenitors and possibly macrophages, predominantly of YS origin.

The fetal liver has long been considered the initial site of B cell commitment beginning at E14 in the mouse, and from then on, the B progenitors expand in a synchronous wave-like pattern reaching a peak in the perinatal stage (132). By functional and phenotypic analysis $\mathrm{AA} 4.1^{+}, \mathrm{Fc} \gamma \mathrm{R}^{+}$or $\mathrm{AA} 4.1^{+}, \mathrm{Sca}-1^{+}, \mathrm{B} 220^{- \text {ve }}$ cells with $\mathrm{B} /$ macrophage potential are detected in E12.5-13 fetal liver (99,133-136). A novel population of $\mathrm{cKit}^{+}, \mathrm{AA} 4.1^{+}$, $\mathrm{CD} 34^{+}, \mathrm{Sca}^{-1}{ }^{-\mathrm{ve}}, \mathrm{CD} 45^{+}, \mathrm{C} 19^{+}$cells $(70 \%$ expressing IL7R $\alpha$ but negative for CD45R/B220) have been reported in E11 AGM and liver that differentiate exclusively into B cells (135). Numerically at E11 these very early pro-B progenitors comprised $\sim 100$ in the AGM region, $\sim 500$ in the liver, with smaller numbers in the blood and yolk sac. Migration of these B progenitors from the AGM to the liver begins at E10 with subsequent increase due to con- 

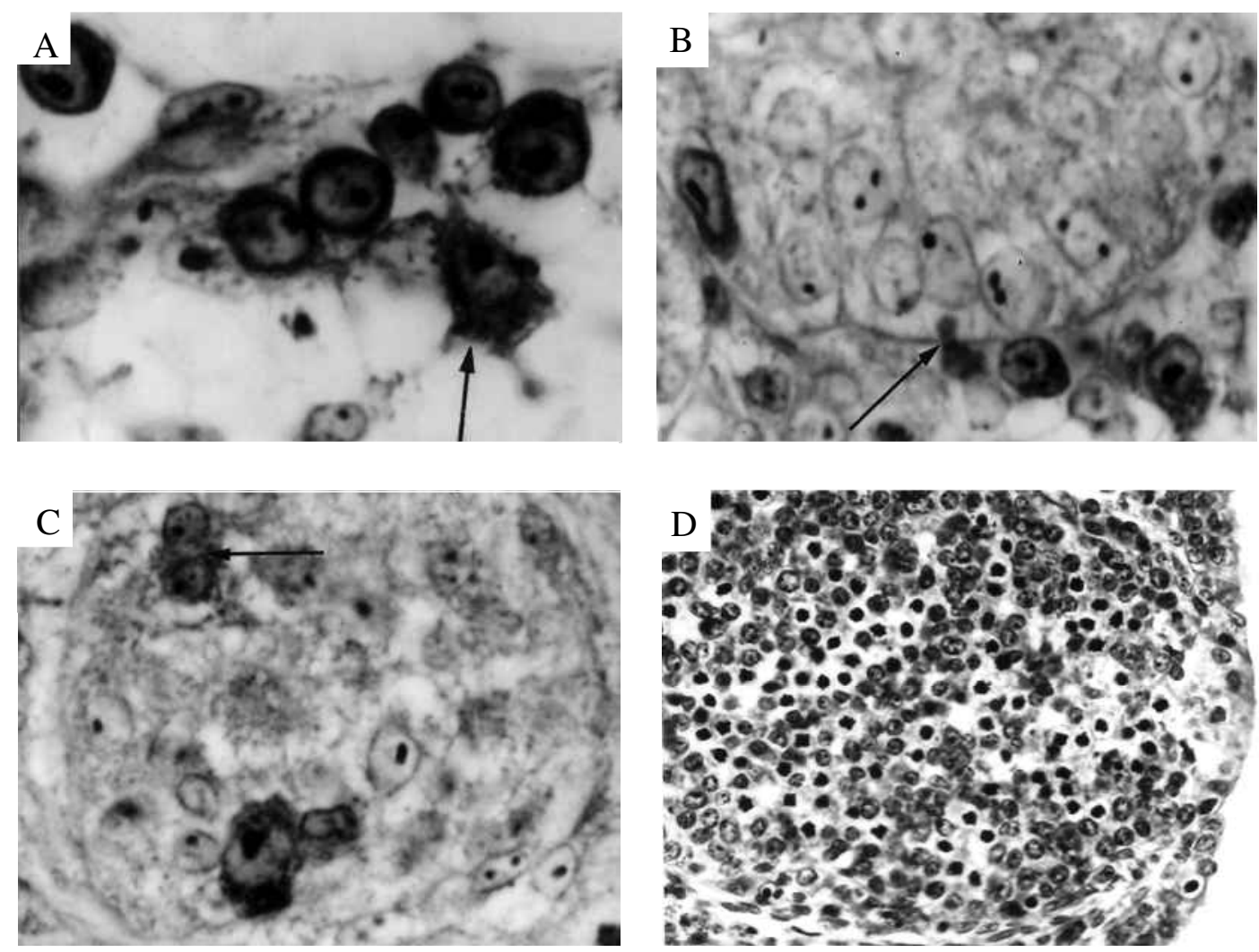

FIG. 4. E14 chick embryo bursa of Fabricius. At this stage the epithelium is budding into the mesenchyme of the tunica propria and chromosome marker studies of parabiosed embryos shows this time to be the onset of bursal chimerism. A. A cluster of basophilic blast cells in a blood vessel in the perifollicular mesenchyme. Note a blast cell extruding pseudopodia, apparently traversing the endothelial lining (arrowed) and a blast cell in the mesenchyme Giemsa stain. $\times 1000$. B. Basophilic blast cells in and around an epithelial bud. A basophilic pseudopod can be seen extending across the epithelial basement membrane from a cell outside the plane of section (arrowed). $\times 750$. C. A circumscribed epithelial follicle containing a large basophilic blast cell, and a pair of smaller basophilic cells, probably a division product of an immigrant blast cell. $\times 750$. D. An E18 bursal follicle from an embryo treated with colcemid to block cells in metaphase (small dark nuclei). Note the predominant lymphoid morphology and high mitotic rate. $\times 250$.

tinued immigration and intra-hepatic expansion. Since HSC are also colonizing the liver at this time, the possibility of intra-hepatic generation of additional $\mathrm{pB}$ from these more primitive cells cannot be excluded. The myeloid suppressing transcription factor Pax 5 plays a critical role in B cell commitment, and Pax5-deficient mice display B cell maturation arrest at the pro-B level (137). The B/macrophage progenitors in the fetal liver and AGM expresses Pax 5 but at a significantly lower level than the adult CLP (136). This observation may account for the retention of macrophage potential in the fetal $\mathrm{B}$ progenitor and complete block of this pathway in the adult CLP. The $\mathrm{pB}$ of Pax5-deficient mice provide long-term reconstitution of the thymus of RAG2-deficient mice and generate mature T cells, and in vitro with appropriate cytokines, can produce $\mathrm{T}$ cells, macrophages, osteoclasts, dendritic cells, granulocytes, and NK cells (137).
The role of the chemokine SDF-1 in promoting the migration of $\mathrm{pB}$ from the AGM region to the liver is suggested by the demonstration that its receptor, CXCR4, is expressed on IL7R $\alpha^{+} \mathrm{pB}$ and SDF-1 induces chemotaxis of these cells (138). Mice with targeted disruption of the SDF-1 or CXCR4 genes display defects in B lymphocyte development in the fetal liver $(139,140)$ that may be attributed to defective colonization of the liver by $\mathrm{pB}$ as well as impairment in B cell proliferation, since SDF-1, acting in synergy with cKit and Flt3 ligands, promotes proliferation of $\mathrm{pB}$ cells (138). The numbers of HSC (CRU) were normal in fetal liver of SDF-1 null embryos between E12.5-E14.5 with a two-fold reduction at E16.5 but normal numbers by E18.5 (141). This contrasted with severe depletion of HSC in E18.5 BM indicating a critical role for SDF-1 in stem cell homing to marrow but not to fetal liver. 


\section{SPLEEN DEVELOPMENT}

The spleen develops as a hematopoietic organ at E13 in the mouse, prior to bone marrow development. Splenic hematopoiesis is initiated at E8 in chick embryos. The splenic primordium appears as a dense syncytial-like mesenchymal thickening in the dorsal mesogastrium interspersed with vascular spaces. Chromosome marker studies in parabiosed and twin chick embryos demonstrated extensive chimerism in the splenic rudiment as early as E12 (14). Cell labeling studies confirmed that circulating cells colonized the chick splenic rudiment as early as E8 (17), and together with embryonic hematopoietic cell reconstitution of irradiated embryos, indicated that splenic colonizing cells were present in the YS and circulation at the time of initiation of splenic hematopoiesis (15). The onset of cell immigration into the developing spleen coincides with the appearance of large immature cells characterized by intense cytoplasmic basophila and prominent nucleoli both in the vascular spaces and perivascular mesenchyme of the spleen (15). In the chick embryo by E9 these basophilic cells appear scattered throughout the mesenchyme and frequently extend long tails of cytoplasm between the reticulum cells for some distance from the main body of the cells. E11 granulopoiesis is extensive and erythropoietic foci develop. In mammals, the fetal liver is the most probable source of cells initially colonizing the spleen rudiment since the AGM and yolk sac are no longer hematopoietic at this stage (E13-14), and the marrow at this early stage is a net importer rather than exporter of cells. CFUGM/BFU-E, CFU-s and HSC are detected by E15 in the murine splenic rudiment and increase in absolute numbers through to 3 weeks post-natally, then progressively decline as the spleen ceases to be a myelopoietic organ (17). Labeled thymic lymphocytes began to localize in the spleen with high efficiency by E17 coinciding with the initiation of lymphopoiesis. In birds and mammals splenic myelopoietic activity progressively declines and the spleen becomes a predominantly lymphopoietic organ.

\section{BONE MARROW DEVELOPMENT}

Bone marrow development begins by penetration of perichondrial mesenchymal cells and blood vessels into the zone of calcified cartilage in the central region of the long bones (142). Vascular cells are recruited by VEGF secreted by hypertrophic chondrocytes and bring along osteoblast precursors and circulating hematopoietic cells, including primitive macrophages (143). The cartilaginous matrix is resorbed and the primordial marrow cavity appears as a mesenchymal network interspersed with a plexus of widely dilated veins. Hematopoiesis is initiated by accumulation of large numbers of undifferentiated basophilic blast cells within the dilated marrow capillaries, beginning at E11-12 in chick, E17 in mouse, and E70-77 in man (17). Avian parabiosis studies demonstrated that circulating stem cells and progenitors colonize the developing marrow beginning at E11-12 (14). Following intravenous injection of tritiated thymidine-labeled embryonic YS or spleen cells into chick embryos, significant numbers of labeled blast cells localized in the marrow at E11 (17). Cells from these tissues also repopulated the marrow when injected into irradiated embryos (15). In the mouse, CFU-GM/BFU-E and CFU-s and HSC appear in the femoral marrow at E17, and the populations double every 34 hrs.

Evidence that fetal liver was the source of stem/progenitor cells for colonizing the marrow came from studies in which rats were injected in utero at E16 with a retroviral vector (144). Clonal identification of viral integration sites showed that fetal liver-derived clones appeared in the marrow and circulated throughout the life of the animals. The role of SDF-1 produced by marrow stromal cells in the chemoattraction of $\mathrm{CXCR} 4^{+} \mathrm{HSC}$ is well established in the adult (145), and the failure of development of marrow hematopoiesis in mice with inactivation of the CXCR4/SDF-1 pathway $(139,140)$ strongly suggests that the initial wave of HSC migration is also SDF-1 dependent. In the marrow of embryonic SDF-1 $-/-$ mice at E18.5 the numbers of HSC, Gr-1+ (myeloid), and B220/CD19+ B lymphoid cells were severely reduced, but numbers of Ter119+ erythroid cells were normal or only modestly reduced (141). SDF-1 in the mesenchymal cells adjacent to endothelial cells appears to play a critical role in colonization of BM by HSC and myeloid and lymphoid progenitors. In rodents, the marrow progressively expands in the first two months of postnatal life, associated with a decline in hepatic hematopoiesis in the first week of life and a decline of splenic hematopoiesis after the third week.

\section{CONCLUSIONS}

The use of various cell marker systems has revealed the dynamic nature of cell migration between developing hematopoietic and lymphoid organs. Hematopoietic stem cells with lymphomyeloid potential are the most likely candidates for cells trafficking from the YS and AGM to fetal liver, spleen, and bone marrow, while lymphoid restricted progenitors appear more likely for primary lymphoid organ colonization. The long debate over the respective roles of YS and AGM in generating the HSC for subsequent hematopoietic development is near a resolution since definitive HSC capable of colonizing the fetal liver first arise in the yolk sac while HSC capable of re- 
populating adult animals first arises in AGM and shortly thereafter in YS, with both sources participating in liver colonization. A central theme of these developmental observations is that stem cells (and in lymphoid pathways, $\mathrm{B}$ or $\mathrm{T}$ restricted progenitor cells) traffic from their sites of origin to specific niches within other organs that support expression of specific differentiation programs. These niches may be at sites of endodermal and mesodermal interaction (yolk sac, thymus, bursa, fetal liver), or be of exclusively mesodermal origin (spleen, marrow). This highly organized system of temporal migration streams of stem/progenitor cells moving through the circulation, and entering appropriate inductive environments seems the antithesis of the emerging concepts of cell plasticity in which hematopoietic stem cell-derived populations can switch not only lineage but also germ layer specificity.

Plasticity has been defined as the ability of adult stem cells to cross lineage barriers and adopt the expression profile and functional phenotype of cells that are unique to other tissues (146). Bone marrow has been identified as a source of cells as diverse as neurons and glia, lung bronchiolar epithelium, and type II pneumocytes, skeletal and cardiac muscle, keratinocytes, intestinal epithelium, hepatocytes, pancreatic beta cells, renal epithelium, mesangial cells, and interstitial cells (reviewed in ref. 146). A number of explanations can be evoked to explain these remarkable observations and these need not all be mutually exclusive. The first may be that some of the observations are erroneous for various technical or methodological reasons, and the irreproducibility of at least some of the data supports this view. Secondly, the marrow may harbor many different types of stem cell. There is no argument about the existence of hematopoietic stem cells, mesenchymal stem cells, and endothelial stem cells within adult marrow (and fetal liver), and it is possible that certain unique features of the marrow provide appropriate niches for the long-term maintenance of many different types of stem cells. These niches may protect stem cells from differentiation pressure to which they are subject once they egress the marrow and home to appropriate target sites, e.g., to muscle or sites of neovascularization in the case of endothelial stem cells. More primitive stem cells may also reside in the marrow, albeit at very low frequencies. Hemangioblasts may persist from early developmental stages since there have been studies where single cell cloning or engraftment experiments have suggested their presence in adult marrow (147-149). While most CD34+, CD133+ marrow cells expressing VEGFR2/KDR/Flk-1 are endothelial progenitor/stem cells, a low percentage of these cells may give rise to hematopoiesis and endothelium (149).

The intimate association between hematopoietic stem cells and endothelium (150) including possibly emperipolesis, protein interchange (151), and cell fusion, does raise concerns about artefacts in this type of study. Perhaps the most remarkable marrow stem cell (or more correctly a stem cell derived by long-term in vitro culture of a CD45-ve marrow population enriched for mesenchymal stem cells under low cell density and highly specific culture conditions), is the Multipotential Adult Progenitor Cell (MAPC) $(152,153)$. These cells can be differentiated in vitro into endodermal, ectodermal, and mesodermal lineages. Murine MAPC when injected into blastocysts contributed to virtually all somatic tissue of the chimeric mice (153). Transplantation of MAPC into sublethally irradiated immunodeficient mice revealed their potential to form CD45+ hematopoietic cells as well as epithelial cells in lung, liver, and intestine. The phenotype and gene expression profile of MAPCs suggest a very primitive cell closer to the primordial germ cell or embryonic stem cell than to either hematopoietic or mesenchymal stem cells. It shares with germ line cells and ES cells the presence of high levels of telomerase, conferring extensive, potentially unlimited, proliferative potential without telomere erosion. The development origins of MAPCs are unknown, if indeed they are normally present in marrow. They may be artificially created by some process of dedifferentiation of mesenchymal stem cells during the prolonged in vitro culture required for their isolation. If they are not some artefact, then they may have some developmental relationship to cells of the inner cell mass that generate ES cells, or the primordial germ cells that are trafficking through the developing embryo at the same time as hematopoietic stem cells are trafficking from yolk sac and AGM to the fetal liver.

If indeed MAPCs bear some developmental relationship to these developmentally primitive, pluripotent stem cells, they should be detected at some stages of development, within the circulation, either trafficking to the fetal liver in early development, or from the liver to the bone marrow at later stages of development. The MAPC has the potential to generate hematopoietic, endothelial, and mesenchymal stem cells and therefore could potentially migrate to a site, e.g., the developing bone, and generate all components of a hematopoietic organ. However, there is no evidence that such a cell plays any role in hematopoietic organogenesis since the evidence points to the local origin of mesenchymal stem cells from the local mesoderm with their differentiation to stroma (154-156) and to osteoblasts which create a critical stem cell-supportive niche for immigrant hematopoietic stem cells (160-161).

A third explanation for plasticity is that a process of transdifferentiation occurs with low frequency, in which a lineage committed cell changes its gene expression pattern to that of a completely different type. A variant of this is that a cell undergoes dedifferentiation and reprogramming along another lineage. Certainly such a pro- 
cess occurs during somatic nuclear transfer to the enucleated oocyte in reproductive and therapeutic cloning. It is probably also occurring during somatic cell fusion that has been shown to occur in a number of experimental systems. Neural stem cells and bone marrow cells have been shown to fuse with ES cells and take on ES properties $(157,158)$. The marrow-derived fusions formed clones that were either tetraploid or hexaploid, and these could form embryoid bodies that differentiated into multiple tissues (159). Fusion was not obtained with purified HSC and it was suggested that fusion involved macrophages (159). The significance of cell fusion has been revealed in a novel transplant system in which marrow was transplanted from mice with Cre recombinase knocked into the CD45 locus promoter and transplanted into a conditional Cre reporter mouse line R26R with the LacZ reporter gene exclusively expressed after excision of the loxP (floxed) stop cassette by Cre-mediated recombination (160). LacZ expressing cells were identified in liver, brain (Purkinje cells), and heart indicating that fusion between hematopoietic-derived cells and differentiated cells occurs in these sites. Cell fusion has been shown to be responsible for hepatic regeneration in other recent studies $(161,162)$ and the intimate association of Kupffer cells of the macrophage lineage with hepatocytes suggests that they are likely the fusion candidates. However, fusion cannot account for all instances of "plasticity" and the in vivo derivation of glucose-competent pancreatic endocrine cells from mouse bone marrow was demonstrated in a system that excluded the possibility of cell fusion (163).

In my forty years of research into the hematopoietic stem cell and its properties, I have seen the "black box" that we labeled "the stem cell" gradually reveal its contents. The evolution of scientific ideas, certainly in cell biology, is generally marked by an initiating concept followed by an oversimplified premature conclusion, followed in turn by a period of anarchy with conflicting interpretations, until finally a consensus is arrived at involving models inherently more complex than initially thought. I would like to believe that we are entering this final phase.

\section{ACKNOWLEDGMENTS}

I thank Kate de Beer for her assistance in the preparation of this document. Also my many fellows and collaborators over the years whose contributions I cite. My apologies to the authors of many worthy studies in this field whose contributions I could not cite due to space constraints. I thank M. Tavian and B. Peault for the photographs shown in Figure 1. Work in my laboratory is supported by National Institutes of Health grant HL61401, National Cancer Institute grant CA59350, and the Gar Reichman Fund of the Cancer Research Institute.

\section{REFERENCES}

1. Anastassova-Kristeva M. (2003). The origin and development of the immune system with a view to stem cell therapy. J Hematother Stem Cell Res 12:137-154.

2. Moore MA and JJ Owen. (1967). Experimental studies on the development of the thymus. J Exp Med 126:715-726.

3. Auerbach R. (1961). Experimental analysis of the origin of cell types in the development of the mouse thymus. Dev Biol 3:336-354.

4. Ackerman GA and RA Knouff. (1965). The epithelial origin of the lymphocytes in the thymus of the embryonic hamster. Anat Rec 152:35-53.

5. Moore MA and JJ Owen. (1966). Experimental studies on the development of the bursa of Fabricius. Dev Biol 14: 40-51.

6. Ackerman GA. (1962). Electron microscopy of the bursa of Fabricius of the embryonic chick with particular reference to the lympho-epithelialnodules. J Cell Biol 13:127146.

7. Cohen N. (1977). Phylogenetic emergence of lymphoid tissue and cells. In: The Lymphocyte. J Marchalonis, ed. Marcel Dekker Inc, New York and Basel, pp 149-196.

8. Turpen JB, EP Volpe and N Cohen. (1973). Ontogeny and peripheralization of thymic lymphocytes. Science 182: 931-933.

9. Bechtold TE, PB Smith and JB Turpen. (1992). Differential stem cell contributions to thymocyte succession during development of Xenopus laevis. J Immunol 148:29752982.

10. Turpen JB, CM Kelley, PE Mead and LI Zon. (1997). Bipotential primitive-definitivehematopoietic progenitors in the vertebrate embryo. Immunity 7:325-334.

11. Ackerman GA and JR Hostetler. (1970). Morphological studies of the embryonic rabbit thymus: the in situ epithelial versus the extrathymic derivation of the initial population of lymphocytes in the embryonic thymus. Anat Rec 166:27-45.

12. Liu CP and R Auerbach. (1991). Ontogeny of murine T cells: thymus-regulated development of $\mathrm{T}$ cell receptorbearing cells derived from embryonic yolk sac. Eur J Immunol 21:1849-1855.

13. Lu LS, SJ Wang and R Auerbach. (1996). In vitro and in vivo differentiationinto B cells, T cells, and myeloid cells of primitive yolk sac hematopoietic precursor cells expanded $>100$-fold by coculture with a clonal yolk sac endothelial cell line. Proc Natl Acad Sci USA 93:1478214787.

14. Moore MA and JJ Owen. (1965). Chromosome marker studies on the development of the haemopoietic system in the chick embryo. Nature 208:986-990.

15. Moore MAS and JTT Owen. (1966). Chromosome marker studies in the irradiated chick embryo. Nature 215:10811082.

16. Moore MAS and JTT Owen. (1967). Stem cell migration in developing myeloid and lymphoid systems. Lancet ii: 658-659.

17. Metcalf D and M Moore. (1971). Haematopoietic Cells. North-Holland Publishing Company, Amsterdam, pp 1550 . 


\section{LYMPHOID SYSTEM ONTOGENY}

18. Jacobson L, E Marks, M Robson, E Gaston and R Zirkle. (1949). The effect of spleen protection on mortality following X-irradiation. J Lab Clin Med 34:1538.

19. Lorenz E, D Uphoff, T Reid and E Shelton. (1951). Modification of irradiation injury in mice and guinea pigs by bone marrow injection. J Natl Cancer Inst 12:197-205.

20. Ford CE, JL Hamerton, DW Barnes and JF Loutit. (1956). Cytological identification of radiation-chimaeras Nature 177:452-454.

21. Micklem H and J Loutit. (1966). Tissue Grafting and Radiation. Academic Press, New York and London, pp 1228.

22. Harris J and C Ford. (1963). Cellular traffic of the thymus: migration of cells from thymic graft to lymph-nodes in mice. Lancet 1:43.

23. Harris JE, CE Ford, DW Barnes and EP Evans. (1964). Evidence from parabiosis for an afferent stream of cells. Nature 201:886-887.

24. Wright DE, AJ Wagers, AP Gulati, FL Johnson and IL Weissman. (2001). Physiological migration of hematopoietic stem and progenitorcells. Science 294:1933-1936.

25. Abkowitz JL, AE Robinson, S Kale, MW Long and J Chen. (2003). Mobilization of hematopoietic stem cells during homeostasis and after cytokine exposure. Blood 102:1249-1253.

26. Owen R. (1945). Immunogenetic consequence of vascular anastamoses between bovine twins. Science 102:400403.

27. Hasek M, A Lengerova and T Hraba. (1961). Transplantation immunity and tolerance. advance. Immunol 1:1.

28. Owen JJ. (1965). Karyotype studies on Gallus domesticus. Chromosoma 16:601-608.

29. Bradley TR and D Metcalf. (1966). The growth of mouse bone marrow cells in vitro. Aust J Exp Biol Med Sci 44: 287-299.

30. Till JE and E McCulloch. (1961). A direct measurement of the radiation sensitivity of normal mouse bone marrow cells. Radiat Res 14:213-222.

31. Haskill JS, TA McNeill and MA Moore. (1970). Density distribution analysis of in vivo and in vitro colony forming cells in bone marrow. J Cell Physiol 75:167-179.

32. Moore MA, TA McNeill and JS Haskill. (1970). Density distribution analysis of in vivo and in vitro colony forming cells in developing fetal liver. J Cell Physiol 75:181192.

33. Haskill JS and MA Moore. (1970). Two dimensional cell separation: comparison of embryonic and adult haemopoietic stem cells. Nature 226:853-854.

34. Trevisan M and NN Iscove. (1995). Phenotypic analysis of murine long-term hemopoietic reconstituting cells quantitated competitively in vivo and comparison with more advanced colony-forming progeny. J Exp Med 181:93-103.

35. Moore MA and D Metcalf. (1970). Ontogeny of the haemopoietic system: yolk sac origin of in vivo and in vitro colony forming cells in the developing mouse embryo. Br. J Haematol 18:279-296.

36. Johnson GR and MA Moore. (1975). Role of stem cell migration in initiation of mouse foetal liver haemopoiesis. Nature 258:726-728.

37. Dieterlen-LievreF. (1975). On the origin of haemopoietic stem cells in the avian embryo: an experimental approach. J Embryol Exp Morphol 33:607-619.

38. Dieterlen-Lievre F, I Godin and L Pardanaud. (1997). Where do hematopoietic stem cells come from? Int Arch Allergy Immunol 112:3-8.

39. Lassila O, J Eskola, P Toivanen, C Martin and F DieterlenLievre. (1978). The origin of lymphoid stem cells studied in chick yold sac-embryo chimaeras. Nature 272:353-354.

40. Lassila O, C Martin, F Dieterlen-Lievre, DG Gilmour, J Eskola and P Toivanen. (1982). Migration of prebursal stem cells from the early chicken embryo to the yolk sac. Scan J Immunol 16:265-268.

41. Medvinsky AL, NL Samoylina, AM Muller and EA Dzierzak. (1993). An early pre-liverintraembryonic source of CFU-S in the developing mouse. Nature 364:64-67.

42. Medvinsky A and E Dzierzak. (1966). Definitive hematopoiesis is autonomously initiated by the AGM region. Cell 86:897-906.

43. Kumaravelu P, L Hook, AM Morrison, J Ure, S Zhao, S Zuyev, J Ansell and A Medvinsky. (2002). Quantitative developmentalanatomy of definitive haematopoietic stem cells/long-term repopulating units (HSC/RUs): role of the aorta-gonad-mesonephros (AGM) region and the yolk sac in colonization of the mouse embryonic liver. Development 129:4891-4899.

44. Baron MH. (2001). Molecular regulation of embryonic hematopoiesis and vascular development: a novel pathway. J Hematother Stem Cell Res 10:587-594.

45. Mikkola HK and SH Orkin. (2002). The search for the hemangioblast. J Hematother Stem Cell Res 11:9-17.

46. Choi K. (2002). The hemangioblast: a common progenitor of hematopoietic and endothelial cells. J Hematother Stem Cell Res 11:91-101.

47. Peault B. (1996). Hematopoietic stem cell emergence in embryonic life: developmental hematology revisited. J Hematother 5:369-378.

48. Baron M. (2001). Induction of embryonic hematopoietic and endothelial stem/progenitor cells by hedgehog-mediated signals. Differentiation 68:175-185.

49. Belaoussoff M., SM Farrington and MH Baron. (1998). Hematopoietic induction and respecification of A-P identity by visceral endoderm signaling in the mouse embryo. Development 125:5009-5018.

50. Byrd N, S Becker, P Maye, R Narasimhaiah, B St-Jacques, X Zhang, J McMahon, A McMahon and L Grabel. (2002). Hedgehog is required for murine yolk sac angiogenesis. Development 129:361-372.

51. Damert A, L Miquerol, M Gertsenstein, W Risau and A Nagy. (2002). Insufficient VEGFA activity in yolk sac endoderm compromises haematopoietic and endothelial differentiation. Development 129:1881-1892.

52. Kabrun N, HJ Buhring, K Choi, A Ullrich, W Risau and G Keller. (1997). Flk-1 expression defines a population of early embryonic hematopoietic precursors. Development 124:2039-2048.

53. Nishikawa SI, S Nishikawa, M Hirashima, N Matsuyoshi and H Kodama. (1998). Progressive lineage analysis by cell sorting and culture identifies $\mathrm{FLK}^{+}{ }^{+} \mathrm{VE}$-cadherin ${ }^{+}$ cells at a diverging point of endothelial and hemopoietic lineages. Development 125:1747-1757. 
54. Yoder MC and K Hiatt. (1997). Engraftment of embryonic hematopoietic cells in conditioned newborn recipients. Blood 89:2176-2183.

55. Palis J, RJ Chan, A Koniski, R Patel, M Starr and MC Yoder. (2001). Spatial and temporal emergence of high proliferative potential hematopoietic precursors during murine embryogenesis. Proc Natl Acad Sci USA 98:4528-4533.

56. Johnson GR and DC Barker. (1985). Erythroid progenitor cells and stimulating factors during murine embryonic and fetal development. Exp Hematol 13:200-208.

57. Huang H and R Auerbach. 1993. Identification and characterization of hematopoietic stem cells from the yolk sac of the early mouse embryo. Proc. Natl Acad Sci USA 90: 10110-10114.

58. Tavian M, MF Hallais and B Peault. (1999). Emergence of intraembryonic hematopoietic precursors in the preliver human embryo. Development 126:793-803.

59. Tavian M, C Robin, L Coulombel and B Peault. (2001). The human embryo, but not its yolk sac, generates lympho-myeloid stem cells: mapping multipotent hematopoietic cell fate in intraembryonic mesoderm. Immunity 15 : 487-495.

60. Cumano A, F Dieterlen-Lievre and I Godin. (2000). The splanchnopleura/AGM region is the prime site for the generation of multipotent hemopoietic precursors, in the mouse embryo. Vaccine 18:1621-1623.

61. Cumano A, JC Ferraz, M Klaine, JP Di Santo and I Godin. (2001). Intraembryonic, but not yolk sac hematopoietic precursors, isolated before circulation, provide long-term multilineage reconstitution. Immunity 15:477-485.

62. Matsuoka S, K Tsuji, H Hisakawa, M Xu, Y Ebihara, T Ishii, D Sugiyama, A Manabe, R Tanaka, Y Ikeda, S Asano and T Nakahata. (2001). Generation of definitive hematopoietic stem cells from murine early yolk sac and paraaortic splanchnopleures by aorta-gonad-mesonephros region-derived stromal cells. Blood 98:6-12.

63. Dagher RN, K Hiatt, C Traycoff, EF Srour and MC Yoder. (1998). c-Kit and CD38 are expressed by long-term reconstituting hematopoietic cells present in the murine yolk sac. Biol Blood Marrow Transplant 4:69-74.

64. Kyba M, RC Perlingeiro and GQ Daley. (2002). HoxB4 confers definitive lymphoid-myeloid engraftment potential on embryonic stem cell and yolk sac hematopoietic progenitors. Cell 109:29-37.

65. Tyan ML and LA Herzenberg. (1968). Studies on the ontogeny of the mouse immune system: II Immunoglobulin-producing cells. J Immunol 101:446-450.

66. Weissman I, V Papaioannou and R Gardner. (1978). Fetal hematopoietic origins of the adult hematolymphoid system. In: Differentiation of Normal and Neoplastic Hematopoietic Cells. B Clarkson, PA Marks and JE Till, eds. Cold Spring Harbor Laboratory, Cold Spring Harbor, NY, pp. 33-47.

67. Huang H, LD Zettergren and R Auerbach. (1994). In vitro differentiation of B cells and myeloid cells from the early mouse embryo and its extraembryonic yolk sac. Exp Hematol 22:19-25.

68. Lu LS and R Auerbach. (1998). Characterization and differentiation of an early murine yolk sac-derived IL-7-independent pre-pro-B cell line. J Immunol 161:1284-1291.
69. Cumano A, C Furlonger and CJ Paige. (1993). Differentiation and characterization of B-cell precursors detected in the yolk sac and embryo body of embryos beginning at the 10- to 12-somite stage. Proc Natl Acad Sci USA 90:6429-6433.

70. Cumano A, F Dieterlen-Lievre and I Godin. (1996). Lymphoid potential, probed before circulation in mouse, is restricted to caudal intraembryonic splanchnopleura. Cell 86:907-916.

71. Ogawa M, S Nishikawa, K Ikuta, F Yamamura, M Naito and K Takahashi. (1988). B cell ontogeny in murine embryo studied by a culture system with the monolayer of a stromal cell clone, ST2: B cell progenitor develops first in the embryonal body rather than in the yolk sac. EMBO J 7:1337-1343.

72. Nishikawa SI, S Nishikawa, H Kawamoto, H Yoshida, M Kizumoto, H Kataoka and Y Katsura. (1998). In vitro generation of lymphohematopoietic cells from endothelial cells purified from murine embryos. Immunity 8:761-769.

73. Tavian M, L Coulombel, D Luton, HS Clemente, F Dieterlen-Lievre and B Peault. (1996). Aorta-associated $\mathrm{CD} 4^{+}$hematopoietic cells in the early human embryo. Blood 87:67-72.

74. Marshall CJ, RL Moore, P Thorogood, PM Brickell, C Kinnon and AJ Thrasher. (1999). Detailed characterization of the human aorta-gonad-mesonephros region reveals morphological polarity resembling a hematopoietic stromal layer. Dev Dyn 215:139-147.

75. Marshall CJ and AJ Thrasher. (2001). The embryonic origins of human haematopoiesis. Br J Haematol 112:838-850.

76. Oberlin E, M Tavian, I Blazsek and B Peauolt. (2002). Blood-forming potential of vascular endothelium in the human embryo. Development 129:4147-4157.

77. Cortes F, C Debacker, B Peault and MC Labastie. (1999). Differential expression of KDR/VEGFR-2 and CD34 during mesoderm development of the early human embryo. Mech Dev 83:161-164.

78. Fraser ST, M Ogawa, RT Yu, S Nishikawa and MC Yoder. (2002). Definitive hematopoietic commitment within the embryonic vascular endothelial-cadherin $(+)$ population. Exp Hematol 30:1070-1078.

79. Marshall CJ, C Kinnon and AJ Thrasher. (2000). Polarized expression of bone morphogenetic protein- 4 in the human aorta-gonad-mesonephros region. Blood 96:15911593.

80. de Bruijn MF, NA Speck, MC Peeters and E Dzierzak. (2000). Definitive hematopoietic stem cells first develop within the major arterial regions of the mouse embryo. EMBO J 19:2465-2474.

81. de Bruijn MF, MC Peeters, T Luteijn, P Visser, NA Speck and E Dzierzak. (2000). CFU-S(11) activity does not localize solely with the aorta in the aorta-gonad-mesonephros region. Blood 96:2902-2904.

82. Oostendorp RA, KN Harvey, N Kusadasi, MF de Bruijn, C Saris, RE Ploemacher, AL Medvinsky and EA Dzierzak. (2002). Stromal cell lines from mouse aorta-gonads-mesonephros subregions are potent supporters of hematopoietic stem cell activity. Blood 99:1183-1189.

83. McGrath KE, AD Koniski, KM Maltby, JK McGann and J Palis. (1999). Embryonic expression and function of the 


\section{LYMPHOID SYSTEM ONTOGENY}

chemokine SDF-1 and its receptor, CXCR4. Dev Biol 213:442-456.

84. North TE, MF de Bruijn, T Stacy, L Talebian, E Lind, C Robin, M Binder, E Dzierzak and NA Speck. (2002). Runx1 expression marks long-term repopulating hematopoietic stem cells in the midgestation mouse embryo. Immunity 16:661-672.

85. Mitjavila-Garcia MT, M Cailleret, I Godin, MM Nogueira, K Cohen-Solal, V Schiavon, Y Lecluse, F Le Pesteur, AH Lagrue and W Vainchenker. (2002). Expression of CD41 on hematopoietic progenitors derived from embryonic hematopoietic cells. Development 129: 2003-2013.

86. Labastie MC, F Cortes, PH Romeo, C Dulac and B Peault. (1998). Molecular identity of hematopoietic precursor cells emerging in the human embryo. Blood 92:36243635 .

87. Cai Z, M de Bruijn, X Ma, B Dortland, T Luteijn, RJ Downing and E Dzierzak. (2000). Haploinsufficiency of AML1 affects the temporal and spatial generation of hematopoietic stem cells in the mouse embryo. Immunity 13:423-431.

88. Cormier F and F Dieterlen-Lievre. (1988). The wall of the chick embryo aorta harbours M-CFC, G-CFC, GM-CFC and BFU-E. Development 102:279-285.

89. Jaffredo T, R Gautier, A Eichmann and F DieterlenLievre. (1998). Intraaortic hemopoietic cells are derived from endothelial cells during ontogeny. Development 125:4575-4583.

90. Jaffredo T, R Gautier, V Brajeul and F Dieterlen-Lievre. (2000). Tracing the progeny of the aortic hemangioblast in the avian embryo. Dev Biol 224:204-214.

91. Martin C, D Beaupain and F Dieterlen-Lievre. (1980). A study of the development of the hemopoietic system using quail-chick chimeras obtained by blastoderm recombination. Dev Biol 75:303-314.

92. Drake CJ and PA Fleming. (2000). Vasculogenesis in the day 6.5 to 9.5 mouse embryo. Blood 95:1671-1679.

93. McGrath KE, AD Koniski, J Malik and J Palis. (2003). Circulation is established in a stepwise pattern in the mammalian embryo. Blood 101:1669-1676.

94. Xu MJ, K Tsuji, T Ueda, YS Mukouyama, T Hara, FC Yang, Y Ebihara, S Matsuoka, A Manabe, A Kikuchi, M Ito, A Miyajima and T Nakahata. (1998). Stimulation of mouse and human primitive hematopoiesis by murine embryonic aorta-gonad-mesonephros-derived stromal cell lines. Blood 92:2032-2040.

95. Sugiyama D, M Ogawa, I Hirose, T Jaffredo, K Arai and K Tsuji. (2003). Erythropoiesis from acetyl LDL incorporating endothelial cells at the preliver stage. Blood 101: 4733-4738.

96. Rehman J, J Li, CM Orschell and KL March. (2003). Peripheral blood "endothelial progenitor cells" are derived from monocyte/macrophages and secrete angiogenic growth factors. Circulation 107:1164-1169.

97. De Palma M, MA Venneri, C Roca and L Naldini. (2003). Targeting exogenous genes to tumor angiogenesis by transplantation of genetically modified hematopoietic stem cells. Nature Med 9:789-795.

98. Kennedy M, M Firpo, K Choi, C Wall, S Robertson, N
Kabrun and G Keller. (1997). A common precursor for primitive erythropoiesis and definitive haematopoiesis. Nature 386:488-493.

99. Lacaud G, L Gore, M Kennedy, V Kouskoff, P Kingsley, C Hogan, L Carlsson, N Speck, J Palis and G Keller. (2002). Runx1 is essential for hematopoietic commitment at the hemangioblast stage of development in vitro. Blood 100:458-466.

100. Choi K, M Kennedy, A Kazarov, JC Papadimitriou and G Keller. (1998). A common precursor for hematopoietic and endothelial cells. Development 125:725-732.

100. Choi K, M Kennedy, A Kazarov, JC Papadimitriou and G Keller. (1998). A common precursor for hematopoietic and endothelial cells. Development 125:725-732.

101. Perlingeiro RC, M Kyba, S Bodie and GQ Daley. (2003). A role for thrombopoietin in hemangioblast development. Stem Cells 21:272-280.

102. Robertson SM, M Kennedy, JM Shannon and G Keller. (2000). A transitional stage in the commitment of mesoderm to hematopoiesis requiring the transcription factor SCL/tal-1. Development 127:2447-2459.

103. Faloon P, E Arentson, A Kazarov, CX Deng, C Porcher, S Orkin and K Choi. (2000). Basic fibroblast growth factor positively regulates hematopoietic development. Development 127:1931-1941.

104. Kumano K, S Chiba, A Kunisato, M Sata, T Saito, E Nakagami-Yamaguchi, T Yamaguchi, S Masuda, K Shimizu, T Takahashi, S Ogawa, Y Hamada and H Hirai. (2003). Notch1 but not Notch2 is essential for generating hematopoietic stem cells from endothelial cells. Immunity 18 : 699-711.

105. Guo Y, R Chan, H Ramsey, W Li, X Xie, WC Shelley, JP Martinez-Barbera, B Bort, K Zaret, M Yoder and R Hromas. (2003). The homeoprotein Hex is required for hemangioblast differentiation. Blood 102:2428-2435.

106. Davidson AJ, P Ernst, Y Wang, MP Dekens, PD Kingsley, J Palis, SJ Korsmeyer, GQ Daley and LI Zon. (2003). cdx 4 mutants fail to specify blood progenitors and can be rescued by multiple hox genes. Nature 425:300-306.

107. Parreira L, H Neves and S Simoes. (2003). Notch and lymphopoiesis: a view from the microenvironment. Semin Immunol 15:81-89.

108. Coltey M, RP Bucy, CH Chen, J Cihak, U Losch, D Char, NM Le Douarin and MD Cooper. (1989). Analysis of the first two waves of thymus homing stem cells and their T cell progeny in chick-quail chimeras. J Exp Med 170:543-557.

109. Nehls M, B Kyewski, M Messerle, R Waldschutz, K Schuddekopf, AJ Smith and T Boehm. (1996). Two genetically separable steps in the differentiation of thymic epithelium. Science 272:886-889.

110. Wilkinson B, JJ Owen and EJ Jenkinson. (1999). Factors regulating stem cell recruitment to the fetal thymus. J Immunol 162:3873-3881.

111. Suniara RK, EJ Jenkinson and JJ Owen. (2000). An essential role for thymic mesenchyme in early $\mathrm{T}$ cell development. J Exp Med 191:1051-1056.

112. Revest JM, RK Suniara, K Kerr, JJ Owen and C Dickson. (2001). Development of the thymus requires signaling through the fibroblast growth factor receptor R2-IIIb. J Immunol 167:1954-1961. 
113. Tsai PT, RA Lee and H Wu. (2003). BMP4 acts upstream of FGF in modulating thymic stroma and regulating thymopoiesis. Blood 102:3947-3953.

114. Ohmura K, H Kawamoto, S Fujimoto, S Ozaki, K Nakao and Y Katsura. (1999). Emergence of T, B, and myeloid lineage-committed as well as multipotent hemopoietic progenitors in the aorta-gonad-mesonephros region of day 10 fetuses of the mouse. J Immunol 163:4788-4795.

115. Kawamoto H, K Ohmura and Y Katsura. (1997). Direct evidence for the commitment of hematopoietic stem cells to T, B and myeloid lineages in murine fetal liver. Int Immunol 9:1011-1019.

116. Kawamoto H, K Ohmura and Y Katsura. (1998). Presence of progenitors restricted to $\mathrm{T}, \mathrm{B}$, or myeloid lineage, but absence of multipotent stem cells, in the murine fetal thymus. J Immunol 161:3799-3802.

117. Kawamoto H, K Ohmura, S Fujimoto and Y Katsura. (1999). Emergence of T cell progenitors without B cell or myeloid differentiation potential at the earliest stage of hematopoiesis in the murine fetal liver. J Immunol 162:2725-2731.

118. Kawamoto H, T Ikawa, K Ohmura, S Fujimoto and Y Katsura. (2000). T cell progenitors emerge earlier than B cell progenitors in the murine fetal liver. Immunity 12 : $441-450$.

119. Kondo M, IL Weissman and K Akashi. (1997). Identification of clonogenic common lymphoid progenitors in mouse bone marrow. Cell 91:661-672.

120. Akashi K, D Traver, M Kondo and IL Weissman. (1999). Lymphoid development from hematopoietic stem cells. Int J Hematol 69:217-226.

121. Itoi M, H Kawamoto, Y Katsura, and T Amagai. (2001). Two distinct steps of immigration of hematopoietic progenitors into the early thymus anlage. Int Immunol 13: 1203-1211.

122. Ohmura K, H Kawamoto, M Lu, T Ikawa, S Ozaki, K Nakao and Y Katsura. (2001). Immature multipotent hemopoietic progenitors lacking long-term bone marrow-reconstituting activity in the aorta-gonad-mesonephros region of murine day 10 fetuses. J Immunol 166: 3290-3296.

123. Douagi I, P Vieira and A Cumano. (2002). Lymphocyte commitment during embryonic development in the mouse. Semin Immunol 14:361-369.

124. Suniara RK, EJ Jenkinson and JJ Owen. (1999). Studies on the phenotype of migrant thymic stem cells. Eur J Immunol 29:75-80.

125. Harman BC, EJ Jenkinson and G Anderson. (2003). Microenvironmental regulation of Notch signaling in $\mathrm{T}$ cell development. Semin Immunol 15:91-97.

126. Schmitt TM and JC Zuniga-Pflucker.(2002). Induction of $\mathrm{T}$ cell development from hematopoietic progenitor cells by delta-like-1 in vitro. Immunity 17:749-756.

127. Allman D, A Sambandam, S Kim, JP Miller, A Pagan, D Well, A Meraz and A Bhandoola. (2003). Thymopoiesis independent of common lymphoid progenitors. Nature Immunol 4:168-174.

128. Kincade PW, JJ Owen, H Igarashi, T Kouro, T Yokota and MI Rossi. (2002). Nature or nurture? Steady-state lymphocyte formation in adult does not recapitulate ontogeny. Immunol Rev 187:116-125.

129. Lind EF, SE Prockop, HE Porritt and HT Petrie. (2001). Mapping precursor movement through the postnatal thymus reveals specific microenvironments supporting defined stages of early lymphoid development. J Exp Med 194:127-134.

130. Houssaint E, A Mansikka and O Vainio. (1991). Early separation of B and T lymphocyte precursors in chick embryo. J Exp Med 174:397-406.

131. Gualdi R, P Bossard, M Zheng, Y Hamada, JR Coleman and KS Zaret. (1996). Hepatic specification of the gut endoderm in vitro: cell signaling and transcriptional control. Genes Dev 10:1670-1682.

132. Strasser A, A Rolink and F Melchers. (1989). One synchronous wave of B cell development in mouse fetal liver changes at day 16 of gestation from dependence to independence of a stromal cell environment. J Exp Med 170: 1973-1986.

133. Cumano A and CJ Paige. (1992). Enrichment and characterization of uncommitted B-cell precursors from fetal liver at day 12 of gestation. EMBO J 11:593-601.

134. Marcos MA, S Morales-Alcelay, IE Godin, F DieterlenLievre, SG Copin and ML Gaspar. (1997). Antigenic phenotype and gene expression pattern of lymphohemopoietic progenitors during early mouse ontogeny. J Immunol 158:2627-2637.

135. de Andres B, P Gonzalo, S Minguet, JA Martinez-Marin, PG Soro, MA Marcos and ML Gaspar. (2002). The first 3 days of B-cell development in the mouse embryo. Blood 100:4074-4081.

136. Mebius RE, T Miyamoto, J Christensen, J Domen, T Cupedo, IL Weissman and K Akashi. (2001). The fetal liver counterpart of adult common lymphoid progenitors gives rise to all lymphoid lineages, $\mathrm{CD} 45^{+} \mathrm{CD} 4^{+} \mathrm{CD} 3^{-}$ cells, as well as macrophages. J Immunol 166:6593-6601.

137. Rolink AG, SL Nutt, F Melchers and M Busslinger. (1999). Long-term in vivo reconstitution of T-cell development by Pax5-deficient B-cell progenitors. Nature 401: 603-606.

138. Egawa $\mathrm{T}, \mathrm{K}$ Kawabata, $\mathrm{H}$ Kawamoto, $\mathrm{K}$ Amada, $\mathrm{R}$ Okamoto, N Fujii, T Kishimoto, Y Katsura and T Nagasawa. (2001). The earliest stages of B cell development require a chemokine stromal cell-derived factor/pre-B cell growth-stimulating factor. Immunity 15:323-334.

139. Nagasawa T, S Hirota, K Tachibana, N Takakura, S Nishikawa, Y Kitamura, N Yoshida, H Kikutani and T Kishimoto. (1996). Defects of B-cell lymphopoiesis and bone-marrow myelopoiesis in mice lacking the $\mathrm{CXC}$ chemokine PBSF/SDF-1. Nature 382:635-638.

140. Ma Q, D Jones, PR Borghesani, RA Segal, T Nagasawa, T Kishimoto, RT Bronson and TA Springer. (1998). Impaired B-lymphopoiesis, myelopoiesis, and derailed cerebellar neuron migration in CXCR4- and SDF-1-deficient mice. Proc Natl Acad Sci USA 95:9448-9453.

141. Ara T, K Tokoyoda, T Sugiyama, T Egawa, K Kawabata and T Nagasawa. (2003). Long-term hematopoietic stem cells require stromal cell-derived factor-1 for colonizing bone marrow during ontogeny. Immunity 19:257-267. 


\section{LYMPHOID SYSTEM ONTOGENY}

142. Moore M. (2003). In vitro and in vivo hematopoiesis. In: Atlas of Blood Cells: Function and Pathology. GC Zucker-Franklin, ed. Edi. Ermes, Milan, pp 1-38.

143. Blazsek I, J Chagraoui and B Peault. (2000). Ontogenic emergence of the hematon, a morphogenetic stromal unit that supports multipotential hematopoietic progenitors in mouse bone marrow. Blood 96:3763-3771.

144. Clapp DW, B Freie, WH Lee and YY Zhang. (1995). Molecular evidence that in situ-transduced fetal liver hematopoietic stem/progenitor cells give rise to medullary hematopoiesis in adult rats. Blood 86:2113-2122.

145. Jo DY, S Rafii, T Hamada and MA Moore. (2000). Chemotaxis of primitive hematopoietic cells in response to stromal cell-derived factor-1. J Clin Invest 105:101111.

146. Herzog EL, L Chai and DS Krause. (2003). Plasticity of marrow-derived stem cells. Blood 102:3483-3493.

147. Bailey AS, S Jiang, M Afentoulis, CI Baumann, DA Schroeder, SB Olson, MH Wong and WH Fleming. (2004). Transplanted adult hematopoietic stem cells differentiate into functional endothelial cells. Blood 103: 13-19.

148. Grant MB, WS May, S Caballero, GA Brown, SM Guthrie, RN Mames, BJ Byrne, T Vaught, PE Spoerri, AB Peck and EW Scott. (2002). Adult hematopoietic stem cells provide functional hemangioblast activity during retinal neovascularization Nature Med 8:607-612.

149. Pelosi E, M Valtieri, S Coppola, R Botta, M Gabbianelli, V Lulli, G Marziali, B Masella, R Muller, C Sgadari, U Testa, G Bonanno and C Peschle. (2002). Identification of the hemangioblast in postnatal life. Blood 100:32033208.

150. Feugier P, DY Jo, JH Shieh, KL Mackenzie, S Rafii, RG Crystal and MA Moore. (2002). Ex vivo expansion of stem and progenitor cells in co-culture of mobilized peripheral blood $\mathrm{CD} 34^{+}$cells on human endothelium transfected with adenovectorsexpressing thrombopoietin, c-kit ligand, and Flt-3 ligand. J Hematother Stem Cell Res 11: 127-138.

151. Moldenhauer A, M Nociari, G Lam, A Salama, S Rafii and M Moore. (2003). Tumor necrosis factor alpha-stimulated endothelium: An inducer of dendritic cell development from hematopoietic progenitors and myeloid leukemic cells. Stem Cells (in press).

152. Reyes M, T Lund, T Lenvik, D Aguiar, L Koodie and CM Verfaillie. (2001). Purification and ex vivo expansion of postnatal human marrow mesodermal progenitor cells. Blood 98:2615-2625.

153. Jiang Y, BN Jahagirdar, RL Reinhardt, RE Schwartz, CD Keene, XR Ortiz-Gonzalez, M Reyes, T Lenvik, T Lund, M Blackstad, J Du, S Aldrich, A Lisberg, WC Low, DA Largaespada and CM Verfaillie. (2002). Pluripotency of mesenchymal stem cells derived from adult marrow. Nature 418:41-49.

154. Koc ON, C Peters, P Aubourg, S Raghavan, S Dyhouse, R DeGasperi, EH Kolodny, YB Yoseph, SL Gerson, HM Lazarus, AI Caplan, PA Watkins and W Krivit. (1999). Bone marrow-derived mesenchymal stem cells remain host-derived despite successful hematopoietic engraftment after allogeneic transplantation in patients with lysosomal and peroxisomal storage diseases. Exp Hematol 27:1675-1681.

155. Waller EK, J Olweus, F Lund-Johansen, S Huang, M Nguyen, GR Guo and L Terstappen. (1995). The "common stem cell" hypothesis reevaluated: human fetal bone marrow contains separate populations of hematopoietic and stromal progenitors. Blood 85:2422-2435.

156. Simmons PJ, D Przepiorka, ED Thomas and B TorokStorb. (1987). Host origin of marrow stromal cells following allogeneic bone marrow transplantation. Nature 328:429-432.

157. Zhang J, C Niu, L Ye, H Huang, X He, WG Tong, J Ross, J Haug, T Johnson, JQ Feng, S Harris, LM Wiedemann, Y Mishina and L Li. (2003). Identification of the haematopoietic stem cell niche and control of the niche size. Nature 425:836-841.

158. Calvi LM, GB Adams, KW Weibrecht, JM Weber, DP Olson, MC Knight, RP Martin, E Schipani, P Divieti, FR Bringhurst, LA Milner, HM Kronenberg and DT Scadden. 2003. Osteoblastic cells regulate the haematopoietic stem cell niche. Nature 425:841-846.

159. Terada N, T Hamazaki, M Oka, M Hoki, DM Mastalerz, Y Nakano, EM Meyer, L Morel, BE Petersen and EW Scott. (2002). Bone marrow cells adopt the phenotype of other cells by spontaneous cell fusion. Nature 416:542545.

160. Alvarez-Dolado M, R Pardal, JM Garcia-Verdugo, JR Fike, HO Lee, K Pfeffer, C Lois, SJ Morrison and A Alvarez-Buylla. (2003). Fusion of bone-marrow-derived cells with Purkinje neurons, cardiomyocytes and hepatocytes. Nature 425:968-973.

161. Vassilopoulos G, PR Wang and DW Russell. (2003). Transplanted bone marrow regenerates liver by cell fusion. Nature 422:901-904.

162. Wang X, H Willenbring, Y Akkari, Y Torimaru, M Foster, M Al-Dhalimy, E Lagasse, M Finegold, S Olson and M Grompe. (2003). Cell fusion is the principal source of bone-marrow-derived hepatocytes. Nature 422:897901.

163. Ianus A, GG Holz, ND Theise and MA Hussain. (2003). In vivo derivation of glucose-competent pancreatic endocrine cells from bone marrow without evidence of cell fusion. J Clin Invest 111:843-850.

Address reprint requests to:

Dr. Malcolm A.S. Moore

Cell Biology Program

Memorial Sloan-Kettering Cancer Center

1275 York Avenue

New York, NY 10021

E-mail:m-moore@ski.mskcc.org

Received December 15, 2003; accepted December 15, 2003. 